OPEN ACCESS

Edited by:

Manfred B. Lutz,

Universität Würzburg, Germany

Reviewed by:

Silvano Sozzani,

Università degli Studi di Brescia, Italy Amanda S. MacLeod,

Duke University, United States

*Correspondence:

Joost J. Oppenheim

oppenhej@mail.nih.gov

De Yang

yangd@mail.nih.gov

Specialty section:

This article was submitted to Antigen Presenting Cell Biology,

a section of the journal

Frontiers in Immunology

Received: 22 August 2018 Accepted: 04 December 2018

Published: 18 December 2018

Citation:

Alam MM, Yang D, Trivett A, Meyer TJ and Oppenheim JJ (2018) HMGN1 and R848 Synergistically Activate

Dendritic Cells Using Multiple Signaling Pathways.

Front. Immunol. 9:2982. doi: 10.3389/fimmu.2018.02982

\section{HMGN1 and R848 Synergistically Activate Dendritic Cells Using Multiple Signaling Pathways}

\author{
Md Masud Alam ${ }^{1}$, De Yang ${ }^{1 *}$, Anna Trivett ${ }^{1}$, Thomas J. Meyer ${ }^{2}$ and Joost J. Oppenheim ${ }^{1 *}$ \\ ${ }^{1}$ Cancer and Inflammation Program, Frederick National Laboratory for Cancer Research, Center for Cancer Research, \\ National Cancer Institute, Frederick, MD, United States, ${ }^{2}$ Advanced Biomedical Computational Science, Frederick National \\ Laboratory for Cancer Research sponsored by the National Cancer Institute, National Institutes of Health, Bethesda, MD, \\ United States
}

High mobility group nucleosome-binding protein 1 (HMGN1 or N1) is a Th1-polarizing alarmin, but alone is insufficient to induce antitumor immunity. We previously showed that combination of $\mathrm{N} 1$ and R848, a synthetic TLR7/8 agonist, synergistically activates dendritic cells (DCs) and induces therapeutic antitumor immunity, however, it remained unclear how $\mathrm{N} 1$ and R848 synergistically activate DCs. Here, we show that co-stimulation with $\mathrm{N} 1$ and R848 of human monocyte-derived DCs (MoDCs) markedly upregulated DC's surface expression of CD80, CD83, CD86, and HLA-DR, as well as synergistic production of pro-inflammatory cytokines including IL-12p70, IL-1 $\beta$, and TNF- $\alpha$. This combination also synergistically activated NF-kB and multiple MAPKs that are involved in DC maturation. Moreover, N1 and R848 synergistically increased nuclear translocation of interferon (IFN) regulatory transcription factors (e.g., IRF3 and IRF7) and promoted the expression of type 1 IFNs such as IFN- $\alpha 2$, IFN- $\alpha 4$, and IFN- $\beta 1$. Similar signaling pathways were also induced in mouse bone marrow-derived DCs (BMDCs). RNA-seq analysis in human MoDCs revealed that N1 plus R848 synergistically upregulated the expression of genes predominantly involved in DC maturation pathway, particularly genes critical for the polarization of Th1 immune responses (e.g., IL12A, IL12B, and IFNB1, etc.). Overall, our findings show that (1) N1 synergizes with R848 in activating human and mouse DCs and (2) the synergistic effect based on various intracellular signaling events culminated in the activation of multiple transcriptional factors. These findings have important implications for future clinical trials since N1 and R848 synergistically promoted optimal Th1 lineage immune responses resulting in tumor rejection in mice.

Keywords: TLR, HMGN1, R848, IFN, NF-КB, MAPK, Th1 polarization, dendritic cell

\section{INTRODUCTION}

Immunotherapy is based on the hypothesis that patients' immune systems can be stimulated to attack the malignant tumor. This idea is based on Coley's observations in 1891 that injection of bacteria or bacterial products into cancer patients resulted in an excellent antitumor effect on bone and soft tissues sarcomas (1). Although the mechanisms by which bacteria or bacterial products induced suppression of malignant tumors were not identified in Coley's time, these products are presumably sensed by Toll-like receptor (TLR) signaling pathways of host cells, as discovered by 
more recent scientific advances. These TLR-mediated signaling pathways play an important role in the induction of innate and adaptive immune responses. Thirteen distinct TLRs have been discovered in mammals and dendritic cells (DCs) expressing these receptors are activated by TLR agonists $(2,3)$. DCs in turn activate $\mathrm{T}$ cells by delivering antigenic signals, co-stimulatory signals as well as cytokine signals. We have therefore chosen to use TLR ligands to treat tumors in mice based on their great capacity to stimulate DCs.

HMGN1 (High mobility group nucleosome-binding protein $1, \mathrm{~N} 1$ ), an endogenous protein that is an alarmin activator of TLR4, has been shown to be a potential inducer of antitumor immunity (4) and a consistent potent immune stimulating alarmin in the induction of adaptive immune responses (4-6). N1 activates DCs in a MyD88 (myeloid differentiation primary response gene 88) and TRIF (TIR domain containing adaptor protein inducing IFN- $\beta$ ) dependent manner (4). It is a unique alarmin that binds to a site distinct from where LPS interacts on MD2 in the TLR4 receptor complex. Furthermore, N1 still has a minor activating effects on cells from $\mathrm{C} 3 \mathrm{H} / \mathrm{HeJ}$ and TLR4 knockout mice using an unidentified pathway. In addition, N1 induces migration of DCs in vitro and recruitment in vivo through GiPCR mediated signaling pathways (our unpublished data). N1 enhances antigen-specific immune response with increased production of IL-12 and induces T-helper type 1 (Th1) polarization in mouse models $(4,7)$. IL-12 is a DCderived cytokine inducer of IFN- $\gamma$ production and a potent inducer of Th1 responses, that bridges innate and adaptive immune responses (8). N1 contributes to the induction of antitumor immune responses against mouse thymoma as well as melanoma and can be used as an effective prophylactic anticancer immunoadjuvant (9). However, N1 alone was unable to therapeutically cure established mouse tumors. Since combined activation of multiple TLR pathways can potentially result in more potent agonistic effects on host immune responses (10), we therefore screened various other TLR agonists to determine the one that could synergize with N1 for the activation of DCs, and established that R848, when combined with $\mathrm{N} 1$, resulted in maximal activation of DC as well as induction of antitumor immunity (11).

R848, an antiviral imidazoquinoline derivative, activates immune cells through TLR7 and/or TLR8 in a MyD88dependent manner (12). Murine TLR7 is clearly sensitive to R848 because $\mathrm{TLR7}^{-1-}$ mice fail to respond to R848, even though TLR8 is present in the immune cells $(13,14)$. TLR $8^{-/-}$murine DCs have increased TLR7 expression and ultimately manifest a potent response to R848 $(13,14)$. No specific ligand for murine TLR8 is known. Nevertheless, a study of TLR $8^{-/-}$mice indicated that TLR8 regulates TLR7 expression and protects mice from autoimmunity, since TLR8 ${ }^{-/-}$mice, but not TLR8 ${ }^{-/-}$TLR7 ${ }^{-/-}$ mice, developed features of lupus-like syndrome (15). In mouse studies, R848 was shown to act as an adjuvant able to promote an adaptive immune response to co-administered antigens (16).

The combination of N1 plus R848 can synergistically induce the maturation of human and mouse DCs (11), however, it remains unknown how N1 plus R848 activates DCs in a synergistical manner. Here we show that the synergistic properties of $\mathrm{N} 1$ plus $\mathrm{R} 848$ on DC maturation are elicited through synergistic activation of nuclear factor (NF)- $\kappa \mathrm{B}$, mitogen activated protein kinases (MAPK), interferon regulatory factor (IRF)-3 as well as IRF7 signaling pathways. DCs exhibit synergistic upregulation of co-stimulatory molecules (CD80, $\mathrm{CD} 83$, and CD86) and produced high levels of pro-inflammatory cytokines (IL-12p70, IL-1 $\beta$, and TNF- $\alpha$ ) as well as type 1 IFN (such as IFN- $\alpha 2$, IFN- $\alpha 4$, and IFN- $\beta 1$ ) in response to treatment with N1 plus R848. RNA-seq and allogeneic mixed lymphocyte reaction (MLR) studies revealed that treatment with N1 plus R848 synergistically activated human DCs toward the direction of preferentially inducing Th1 polarization. Our study shows for the first time that synergistic activation of NF- $\mathrm{B}$, MAPK, IRF3, and IRF7 transcription factors are responsible for the synergistic pro-inflammatory cytokine as well as type 1 IFN production in response to combined stimulation with N1 plus R848 in both human monocyte derived (Mo)-DCs as well as mouse bone marrow derived (BM)-DCs.

\section{MATERIALS AND METHODS}

\section{Mice and Reagents}

Male wild-type C57BL/6 mice, 7-8 weeks old were provided by the animal production facility of the National Cancer Institute (NCI). National Cancer Institute (NCI) is approved by the American association for the accreditation of laboratory animal care and follows the public health service policy for the care and use of laboratory animals. Animal care was provided in accordance with the procedures outlined in the guide for care and use of laboratory animals (National research council, Washington DC). Recombinant human or mouse GM-CSF, IL4 were purchased from PeproTech. R848 was obtained from Invivogen. Recombinant N1 was generated in insect cells and purified as previously described $(4,17)$.

\section{Isolation and Purification of Cells}

Human peripheral blood cell samples were obtained from healthy donors (Transfusion medicine department, Clinical center, National institutes of health, Bethesda, MD, with an approved human subject agreement) by leukopheresis. Peripheral blood mononuclear cells (PBMC) were isolated by Ficol-Hypaque (Sigma-Aldrich, St-Louis, MO) density gradient centrifugation. Monocytes and CD4+ T cells were purified (>95\%) from PBMC with the use of MACS CD14 monocyte and CD4 T isolation kits (Miltenyl Biotech, Auburn, CA) according to the manufacturer instructions $(4,5)$. Mouse bone marrow derived hematopoietic progenitor cells (HPCs) were prepared from C57BL/6 wild type mice (Male 7-8 weeks old) by flushing from femur and tibia with the depletion of red blood cell (RBCs) by ammonium chloride treatment [ACK lysing buffer, Quality Biological] (18).

\section{Generation and Stimulation of Human MoDCs and Mouse BMDCs}

Human MoDC and mouse bone marrow-derived DC (BMDC) generation were performed as described previously (4). Briefly, human MoDCs were generated by culturing purified monocytes at $5 \times 10^{5}$ cells $/ \mathrm{ml}$ in complete RPMI 1,640 medium (RPMI 
1,640 medium [Mediatech Inc] supplemented with 10\% FBS [GemCell], $2 \mathrm{mM}$ glutamine [Lonza], $25 \mathrm{mM}$ HEPES [Quality Biological], $100 \mathrm{U} / \mathrm{ml}$ penicillin [Lonza], $100 \mu \mathrm{g} / \mathrm{ml}$ streptomycin [Lonza], and $50 \mu \mathrm{M}$ of 2-Mercaptoethanol [Sigma]) containing $50 \mathrm{ng} / \mathrm{ml}$ human GM-CSF and IL-4 at $37^{\circ} \mathrm{C}$ in a humidified $\mathrm{CO}_{2}(5 \%)$ incubator for 5 days with $50 \%$ of the culture medium replaced with prewarmed fresh complete RPMI 1,640 medium containing human GM-CSF and IL-4 at the same concentration on days 3. On the 5th day of culture, cells in suspension were harvested and used as immature MoDCs (purity almost $99.99 \%$ observed under microscopy) for subsequent experiments. Mouse BMDCs were generated by culturing mouse HPCs isolated from the femurs and tibias in complete RPMI 1,640 containing $20 \mathrm{ng} / \mathrm{ml}$ mouse GM-CSF for 6 days. On the 2 nd and 4 th days of culture, non-adherent cells were removed by gentle pipetting and the remaining adherent cells were cultured in the complete medium containing mouse GM-CSF at the same concentration as indicated above. On the 6th day of culture, cells in suspension were harvested as immature DCs and used for subsequent experiments. Immature human MoDCs and mouse BMDCs were stimulated with $\mathrm{N} 1$ and/or R848, for $30 \mathrm{~min}$ (') to $48 \mathrm{~h}$ at $37^{\circ} \mathrm{C}$ in a $\mathrm{CO}_{2}$ incubator before being analyzed for phenotype, antigenpresenting function, and signaling.

\section{Assessment of Human MoDC and Mouse BMDC Phenotypes Through Surface FACS Staining}

Stimulated and non-stimulated DCs $\left(10^{6}\right.$ cells/samples $)$ were first washed three times with fluorescence activated cell sorter (FACS) buffer (PBS [Mediatech Inc], 2\% FBS, 0.05\% $\mathrm{NaN}_{3}$ [ThermoFisher Scientific], $\mathrm{pH}$ 7.4) and blocked for $10 \mathrm{~min}$ at $4{ }^{\circ} \mathrm{C}$ in FACS buffer containing $2 \%$ human $\mathrm{AB}$ serum (Sigma Aldrich) and/or 2\% normal mouse serum (C57BL/6 mouse) (11). Subsequently, the cells were stained with monoclonal antibodies against human CD80 (BD Pharmingen, FITC conjugated IgG1, $\kappa$, clone L307.4), CD83 (BD Pharmingen, PE conjugated IgG1, $\kappa$, clone HB15e), CD86 (BD Pharmingen, PerCP-Cy5.5 conjugated IgG1, $\kappa$, clone 2331), HLA-DR (Biolegend, PB conjugated IgG2b, $\kappa$, clone LN3) or mouse CD80 (BD Pharmingen, eFluor 450 conjugated IgG, $\kappa$, clone 16-10A1), CD86 (BD Pharmingen, FITC conjugated IgG2a, $\kappa$, clone GL1), I-A/E (Biolegend, PE/Cy7 conjugated IgG2b, $\kappa$, clone M5/114.15.2) with the isotype matched control antibodies at $4{ }^{\circ} \mathrm{C}$ for $20-$ $30 \mathrm{~min}$. Then the cells were washed once with flow cytometry buffer and twice with PBS, suspended in PBS and analyzed the expression of surface molecules on LSR II flowcytometry (BD FACSCalibur). Data were analyzed by FlowJo software version 10.1 .

\section{Measurement of Cytokine Levels in Culture Supernatants of Human MoDCs and Mouse BMDCs}

Multiple cytokines in the culture supernatants of human and mouse DCs were measured using V-PLEX (IL-1 $\beta$, TNF- $\alpha$, and IL-12p70) and U-PLEX (IFN- $\gamma$ ) ultrasensitive plate assays (Meso Scale Discovery) (19). The plates were analyzed using a sector image 2,400 (Meso Scale Discovery) according to the manufactures protocol. The detection limits of the human cytokines are IL-12p70: $0.117 \mathrm{pg} / \mathrm{ml}$; IL-1 $\beta$ : $0.137 \mathrm{pg} / \mathrm{ml}$; and TNF- $\alpha$ : $0.0859 \mathrm{pg} / \mathrm{ml}$ and the limits for the mouse cytokines are IL-12-p70: $4.90 \mathrm{pg} / \mathrm{ml}$; IL-1 $\beta$ : $0.0793 \mathrm{pg} / \mathrm{ml}$; and TNF- $\alpha$ : $0.0327 \mathrm{pg} / \mathrm{ml}$. The data comparing the means of the stimulated samples to those of non-stimulated control were analyzed by GraphPad Prism version 7 .

\section{MLR}

Allogenic MLR was performed as previously described (5). Briefly, human MoDCs $\left(4 \times 10^{6}\right.$ cells $/ 8 \mathrm{ml} /$ well $)$ were cultured in 6-well plates and treated with $\mathrm{N} 1$ and/or R848 for 2 days at $37^{\circ} \mathrm{C}$ in a humidified air with a $5 \% \mathrm{CO}_{2}$. The treated DCs were co-cultured with purified allogenic CD4+ T ( $10^{5}$ cells/well $)$ cells at 1:250,1:750,1:2,250,1:6,750, and 1:20,250 ratios in a complete medium $(0.2 \mathrm{ml} /$ well $)$ in a triplicate in 96 -well plate for 4 days at $37^{\circ} \mathrm{C}$. After 4 days of co-culture, the cells were pulsed with $1.0 \mu \mathrm{Ci} /$ well $\left[{ }^{3} \mathrm{H}\right]$-TdR (New England Nuclear) for an additional $18 \mathrm{~h}$ before harvesting. ${ }^{3} \mathrm{H}-\mathrm{TdR}$ incorporation was measured with microbeta counter (Wallace, Gaithersburg, MD) for the proliferative response of allogenic CD4+ T cells. Alternatively, the supernatants of the MLR culture in a complete medium (0.4 $\mathrm{ml} /$ well) in 48-well plates at 3 days were collected for cytokine quantitation. Data were analyzed by GraphPad Prism version 7.

\section{Analysis of T-bet and Gata-3 Transcription Factor by Intracellular FACS Staining}

Intracellular staining was performed according to the referred eBiosciences staining intracellular protocol assays for FACS. Briefly, human MoDCs $\left(4 \times 10^{6}\right.$ cells $/ 8 \mathrm{ml} /$ well $)$ were cultured in 6-well plates and treated with $\mathrm{N} 1$ and/or R848 for 2 days at $37^{\circ} \mathrm{C}$. The treated DCs were co-cultured with allogenic CD4+ $\mathrm{T}\left(10^{6}\right.$ cells/well $)$ cells at $1: 250$ ratio in a complete medium $(0.4 \mathrm{ml} /$ well $)$ in triplicate in 48 -well plates for 3 days at $37^{\circ} \mathrm{C}$ in a humidified air containing $5 \% \mathrm{CO}_{2}$, with the addition of GolgiPlug cell stimulation cocktail (composed of Phorbol ester, Ionomycin, PMA, Brefeldin A and Monensin from Tonbo Biosciences) for the last $6 \mathrm{~h}$ of co-culture (9). Cells were collected, washed with FACS buffer, blocked with $2 \%$ human AB serum for $10 \mathrm{~min}$ and stained with monoclonal antibodies against human CD4 (Tonbo biosciences, APC-cy7 conjugated IgG1, $\kappa$, clone RPA-T4) for $30 \mathrm{~min}$ at room temperature. Cells were washed (with FACS buffer once and PBS twice), fixed with intracellular fix/perm buffer (Tonbo bioscience; cat. No. TNB-1020-L050) for $18 \mathrm{~h}$ in dark at $4^{\circ} \mathrm{C}$, then washed by adding permeabilization buffer (Tonbo bioscience; cat. No. TNB-1213-L150) to the fixed cells, centrifuged and blocked by $2 \%$ normal mouse serum (made in permeabilization buffer) for $10 \mathrm{~min}$. Subsequently, Cells were incubated with monoclonal antibodies against human $\mathrm{T}$ bet (Biolegend, PB conjugated IgG1, $\kappa$, clone 4B10) and Gata3 (BD Pharmingen, PE conjugated IgG1, $\kappa$, clone L50-823) in permeabilization buffer for $1 \mathrm{~h}$ at room temperature. After three washes with permeabilization buffer, the samples were resuspended in 1\% paraformaldehyde in PBS and data were 
acquired on a LSRII flow cytometer. Flow cytometry data were analyzed using FlowJo software version 10.1.

\section{SDS-PAGE and Western Blot Analysis}

Sodium dodecyl sulfate-polyacrylamide gel electrophoresis (SDSPAGE) and western blot analysis were performed as described previously (20). Briefly, serum starved human MoDCs and mouse BMDCs were incubated for $6 \mathrm{~h}$ with individual or combined ligands for a period as specified. The treated and untreated cells were lysed in SDS whole cell lysis buffer composed of $62.5 \mathrm{mM}$ Tris- $\mathrm{HCl}, \mathrm{pH} 6.8$ (Quality biological) at $25^{\circ} \mathrm{C}$, $2 \% \mathrm{wt} / \mathrm{vol}$ SDS (Quality biological), and $40 \mathrm{mM}$ dithiothreitol (Sigma aldrich) at $10^{7}$ cells $/ \mathrm{ml}$ for $30 \mathrm{~min}$ at room temperature. Nuclear and cytoplasmic proteins were collected using NEPER extraction reagents according to manufacturer's instructions (ThermoFisher Scientific) and quantitated by Pierce BCA protein assay kits (ThermoFisher Scientific). NuPAGE LDS sample buffer (ThermoFisher Scientific) were added to these protein lysates. $1 \times$ NuPAGE MOPS SDS running buffer was used as an electrode buffer. After transfer of separated proteins onto polyvinylidene difluoride (PVDF) membranes (Immobilon, Millipore), the membrane were rinsed with tris-buffered saline (Quality biological) containing 0.05\% tween 20 (Sigma aldrich) (TBST), blocked with blocking buffer $(1 \times$ TBST containing $5 \%$ non-fat milk [BioRad]) at room temperature for $1 \mathrm{~h}$ and incubated overnight at $4^{\circ} \mathrm{C}$ with antibodies (1:1,000 diluted in blocking buffer) against phospho-p38 (Cell signaling technology [CST], T180/Y182), phospho-JNK (CST, T183/185), phosphoCREB (CST, 87G3), phospho-c-Jun (CST, 60A8), phospho-I-кB $\alpha$ (CST, 14D4), phospho-p65 (CST, S536), IRF3 (CST, D83B9), IRF7 (CST, D2A1J, human specific), and IRF7 (Abcam, ab109255, mouse specific) as the first antibody. After washing with TBST, the membranes were reacted with horseradish peroxidase (HRP)conjugated goat anti-rabbit IgG (CST, 7074S) as the secondary antibody (1:2,000 diluted in blocking buffer), washed and developed in the SuperSignal West Dura Extended Duration Substrate (ThermoFisher Scientific). The images were collected using the G BOX Chemi systems (Syngene). Subsequently, the same membrane was stripped by blot stripping buffer (ThermoFisher Scientific) and probed consecutively in the same manner using p38 (CST, 9212S), JNK (CST, 9252S), CREB (CST, 48H2), c-Jun (CST, 60A8), I-кB $\alpha$ (CST, 44D4), lamin B1 (Abcam, D4Q4Z), and GAPDH (CST, 14C10) as the first antibodies. The immunoreactive bands were quantified by densitometry with ImageJ 1.52a software (National Institutes of Health, USA) according to the manufacturer's instructions.

\section{RNA Extraction, cDNA Synthesis and Real-Time (RT)-PCR}

Total RNA from the treated and control DCs was isolated using TRIzol reagent (Invitrogen Life Technologies) according to manufacturer's instructions. The RNA was purified using RNeasy Micro Kit (Qiagen) with an on-column DNase digestion to eliminate possible genomic DNA contamination. Purified RNA (500 ng) was reverse-transcribed to cDNA with QuantiTect Reverse Transcription kit (Qiagen). Twenty nanograms of cDNA was used for qRT-PCRs. qRT-PCRs were performed with a RT ${ }^{2}$
DNA SYBR green ROX kit (Qiagen) on ABI 7,500 Fast RTPCR system to measure the expression of human and mouse cytokines using specific primers obtained from Qiagen (Table S1 in Supplementary Material). $\Delta \mathrm{Ct}$ values were obtained by deducting the raw cycle threshold (Ct values) obtained from $\beta$-Actin mRNA, the internal standard, from the Ct values obtained for investigated genes. For graphical representation, data are expressed as fold mRNA level increase compared to the expression level in unstimulated cells using GraphPad Prism version 7 (11).

\section{RNA-seq Analysis}

Total RNA of stimulated human MoDCs from three donors was isolated using the QIAGEN RNeasy kit according to manufacturer's instructions. The integrity was checked by the RNA integrity number (RIN) value and samples that passed the quality control check were used for sequencing at the NCI, CCR sequencing facility. Briefly, $400 \mathrm{ng}$ of total RNA was used as the input to an mRNA capture with oligo-dT coated magnetic beads. The mRNA is fragmented, and then a random-primed cDNA synthesis is performed (Illumina, Inc.). The resulting doublestrand cDNA is used as the input to a standard Illumina library prep with end-repair, adapter ligation and PCR amplification being performed yielding a sequencing ready library. The final purified product is then quantitated by qPCR (Kapa Biosystems) before cluster generation. Samples were pooled and sequenced on one HiSeq 4,000 run using Illumina TruSeq Stranded Total RNA Kit RS-122-2201. The HiSeq RT Analysis software (RTA v1.18.64) was used for base calling. The Illumina bcl2fastq v2.17 software was used to demultiplex and convert binary base calls and qualities to FASTQ format. RNA-seq NGS-datasets were processed using the CCBR Pipeliner utility (https://github.com/ CCBR/Pipeliner). Briefly, reads were trimmed of low quality bases and adapter sequences were removed using Trimmomatic v0.33 (21). Mapping of reads to the GRCh37 (hg19) human reference genome was performed using STAR v2.5.2b in 2-pass mode (22). Then, RSEM v1.3.0 was used to quantify gene-level expression, with counts normalized to library size as countsper-million (23). Finally, limma-voom v3.34.5 was used for quantile normalization and differential expression (24). The data discussed in this publication have been deposited in NCBI's Gene Expression Omnibus (25) and are accessible through GEO Series accession number GSE121607 (https://www.ncbi.nlm.nih. gov/geo/query/acc.cgi?acc=GSE121607). Genes were considered variable if significantly differentially expressed relative to sham (adjusted $p<0.05$ ) and absolute fold change relative to sham was $\geq 2.0$. Pathway analysis was performed using Ingenuity Pathway Analysis (26) and a pathway was considered significantly activated/deactivated if the absolute activation $z$-score in all contrasts was $\geq 2.0$. Gene ontology (GO) term analysis was performed using ClueGO (27). Expression data were visualized as heat maps using ClustVis (28).

\section{Statistical Analysis}

All experiments were performed at least three times with similar results. The statistical significance between groups were analyzed by using Microsoft Excel and GraphPad Prism version 7. Data are 
expressed as the average (mean $\pm \mathrm{SD}$ ) of multiple experiments. Statistical significance of differences among the groups was determined by an ordinary one-way ANOVA (non-parametric) followed by Tukey's post hoc test with a threshold set as $p<0.05$.

\section{RESULTS}

\section{N1 and R848 Dose Dependently Activate Human MoDCs}

Activation of DCs results in the acquisition of a mature phenotype with upregulation of surface expression of co-stimulatory molecules and the production of proinflammatory cytokines (29). We have previously reported that recombinant protein, $\mathrm{N} 1$ and a synthetic imidazoquinoline, R848 synergistically activates DCs $(4,11)$. To determine the optimal doses of $\mathrm{N} 1$ and R848 to activate human MoDCs, we stimulated pure primary human immature DCs generated from CD14+ monocytes for $48 \mathrm{~h}$, previously determined to be an optimal duration of incubation. We determined the minimal to maximal doses for each of the stimulants (4). The results showed that $\mathrm{N} 1(125,250$, and $500 \mathrm{ng} / \mathrm{ml})$ and $\mathrm{R} 848(15-500 \mathrm{ng} / \mathrm{ml})$ dose-dependently upregulated co-stimulatory (CD80, CD83, and CD86) as well as MHC class II (HLA-DR) molecules, indicating that these human MoDCs acquired phenotypic markers of maturation (Figures 1A,C). N1- and R848-treated human MoDCs each produced more TNF- $\alpha$ protein in a dose-dependent manner but did not elevate IL-12p70 and IL-1 $\beta$ levels (Figures 1B,D). The production of increased TNF- $\alpha$ and induction of phenotypic markers identified the doses yielding optimal responses by activated human MoDCs. Stimulation with $1 \mu \mathrm{g} / \mathrm{ml}$ of reagents as previously reported resulted in suboptimal activation of human MoDCs (4). Therefore, N1 and R848 each induced dose-dependent activation of human MoDCs with $500 \mathrm{ng} / \mathrm{ml}$ yielding maximal effect.

\section{N1 and R848 Result in Dose Dependent Synergistic Activation of Human MoDCs}

Since N1 together with R848 synergize in upregulating the surface expression of co-stimulatory molecules on DCs and synergistically promote the production of pro-inflammatory cytokines by DCs (11), it is essential to determine the doses resulting in optimal synergistic activation of DCs. We therefore determined the effects of different dose ranges of $\mathrm{N} 1(125,250$, and $500 \mathrm{ng} / \mathrm{ml})$ and R848 (15-500 ng/ml) in combination on human MoDCs response at $48 \mathrm{~h}$ (Figures S2A,B, S3A,B, and S4A,B in Supplementary Material, respectively). Concentrations of $250 \mathrm{ng} / \mathrm{ml} \mathrm{N1}$ with $250 \mathrm{ng} / \mathrm{ml} \mathrm{R} 848$ yielded maximal synergistic upregulation of cell surface expression of co-stimulatory (CD80, CD83, CD86, and HLA-DR) molecules (Figures 2A,C) as well as production of pro-inflammatory cytokine (IL-12p70, IL-1 $\beta$, and TNF- $\alpha$ ) proteins (Figures 2B,D) and mRNA levels (Figures S1A-C in Supplementary Material, respectively). The doses of N1 plus R848 at $250 \mathrm{ng} / \mathrm{ml}$ induced about 4-fold higher production of pro-inflammatory cytokines by activated human MoDCs than stimulation by a concentration of $125 \mathrm{ng} / \mathrm{ml}$. Analogous, but suboptimal synergistic responses were also obtained using other doses of $\mathrm{N} 1$ together with R848 (Figures S2A,B, S3A,B, S4A,B, respectively). Although N1 and R848 signaling alone induced only increases in TNF- $\alpha$ levels, the combination of $250 \mathrm{ng} / \mathrm{ml}$ each of $\mathrm{N} 1$ plus R848 led to robust production of IL-12p70, IL-1 $\beta$, and TNF- $\alpha$ by human MoDCs. Therefore, $250 \mathrm{ng} / \mathrm{ml} \mathrm{N1}$ with $250 \mathrm{ng} / \mathrm{ml}$ R848 maximally activated human MoDCs. We subsequently used these doses to obtain signal transduction responses.

\section{N1 and R848 Induced Synergistic Th1 Polarization of Allogeneic Naïve Human CD4+ T Cells}

Previously, it has been reported that N1- or R848-treated DCs have the capacity to stimulate the proliferation of allogeneic naïve CD4+ T cells $(4,30,31)$. To analyze the effect on functional maturation of N1- plus R848-treated human MoDCs, we cocultured the human MoDCs stimulated with N1 at $250 \mathrm{ng} / \mathrm{ml}$ together with $\mathrm{R} 848$ at $250 \mathrm{ng} / \mathrm{ml}$ plus allogeneic naïve CD4+ $\mathrm{T}$ lymphocytes (L) at different human $\mathrm{MoDCs} / \mathrm{L}$ ratio for 5 days to determine the proliferative response of $\mathrm{CD} 4+\mathrm{T}$ (L) cells in MLR's. Human MoDCs treated with the combination of N1 plus R848 synergistically stimulated $\left[{ }^{3} \mathrm{H}\right] \mathrm{TdR}$ incorporation by allogenic CD4+ T cells compared with N1 or R848 alone. Therefore, human MoDCs treated with these TLR ligands exhibited synergistically enhanced capacity to antigenically activate CD4+ T cells to induce an MLR (Figure 3A).

IL-12p70 heterodimer, composed of p35 and p40 chains, promotes the development of naïve $\mathrm{T}$ cells into Th1 cells and resultant IFN- $\gamma$ production (32). Therefore, the cells were cultured for 3 days at a human MoDCs/L ratio of 1:250 to determine the levels of IFN- $\gamma$ as well as Th1 polarizing transcription factor T-bet. Treatment of DCs with N1 plus R848 resulted in a remarkable synergistic upregulation of IFN- $\gamma$ cytokine production (Figure 3B) and the expression of the T-bet transcription factor by the CD4 $+\mathrm{T}$ cells, while each stimulant alone was only minimally active in this respect (Figures $3 \mathbf{C}-\mathbf{E}$ ). The above results indicated that the high levels of cytokines and particularly IL-12p70 secretion by DCs activated with N1 plus R848 synergistically polarize CD4+ T cells toward a Th1 response to a much greater extent than activation with single TLR agonists.

\section{Stimulation of Human MoDCs by N1 Plus R848 Synergistically Activates NF- $\mathrm{B}$ and MAPK Pathways}

In resting cells, the transcription factor NF- $\kappa \mathrm{B}$ exists mainly in the cytosol where it binds to I- $\kappa \mathrm{B} \alpha$. Upon cell activation, I- $\kappa \mathrm{B} \alpha$ is phosphorylated, ubiquitinated, and then degraded leading to the release of NF- $\kappa \mathrm{B}$, which subsequently translocate to the nucleus and causes inflammatory gene transcription $(33,34)$. Therefore, activation of the NF- $\kappa \mathrm{B}$ pathway was determined using degradation of $\mathrm{I}-\kappa \mathrm{B} \alpha$ as a readout. Stimulation with N1 at $250 \mathrm{ng} / \mathrm{ml}$ plus $\mathrm{R} 848$ at $250 \mathrm{ng} / \mathrm{ml}$ synergistically increased phospho-I- $\kappa \mathrm{B} \alpha$, phospho-p65, and nuclear translocation of phospho-p65, as well as decreased $I-\kappa B \alpha$ indicating that this combination of stimulants synergistically activated the 
A

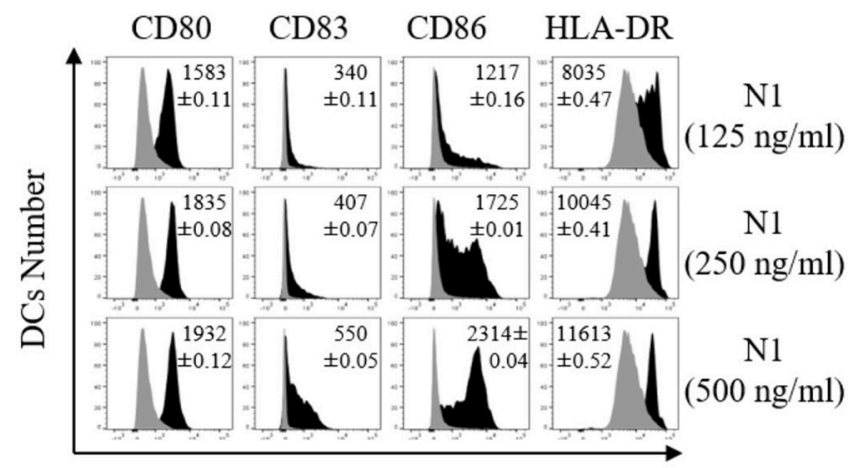

Fluorescence Intensity (log)

C

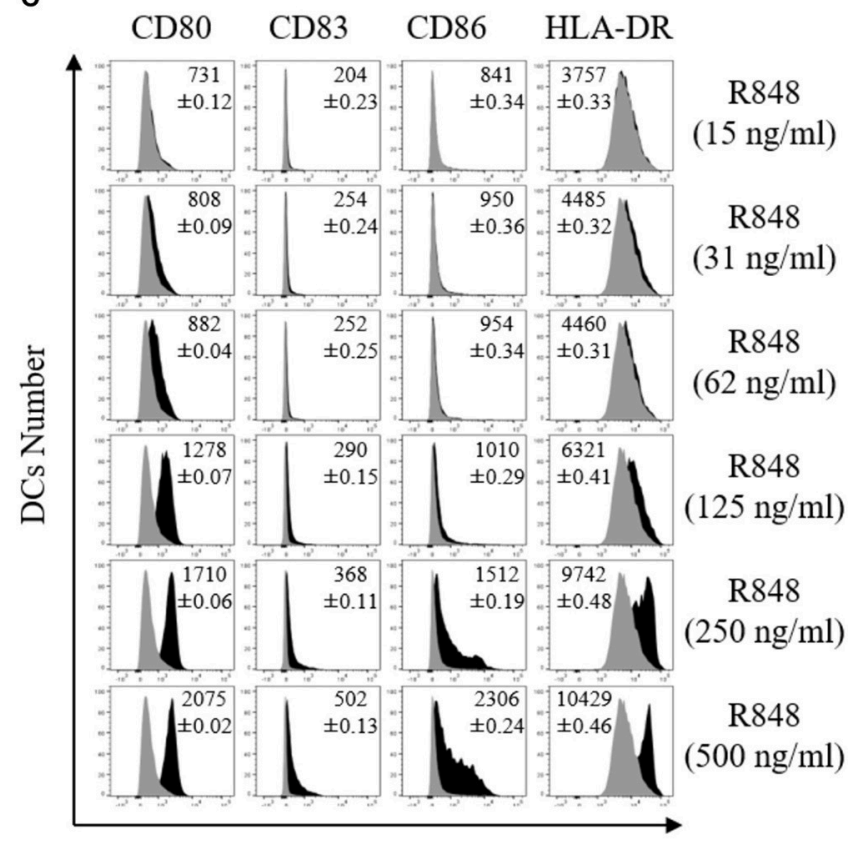

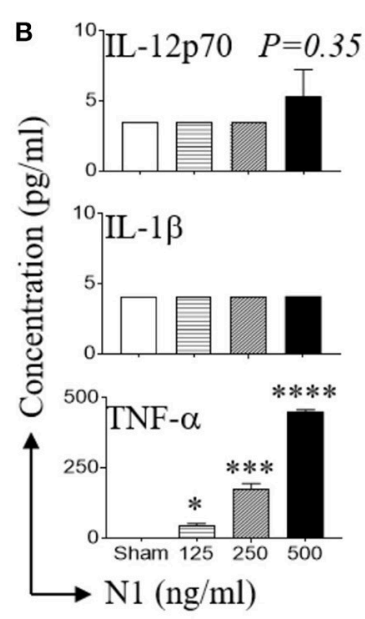

D
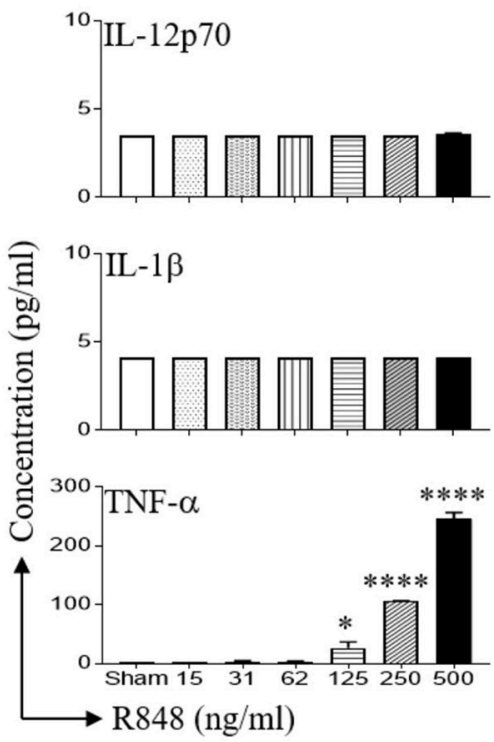

Fluorescence Intensity $(\log )$

FIGURE 1 | N1 and R848 dose dependently induce phenotypic maturation of human MoDCs. (A,C) Human MoDCs were incubated at $5 \times 10^{5}$ cells/ml in the absence (sham) or presence of indicated concentrations of recombinant N1 or R848 for $48 \mathrm{~h}$ before they were immunostained and analyzed by flow cytometry for the expression of the indicated surface molecules. Shown are the overlay histograms (gray area = sham-treated) of one experiment, with the average relative fluorescence intensity (geometric mean \pm SD) of three independent experiments inscribed. (B,D) Cytokine levels in the culture supernatants of DCs treated with N1 or R848 at indicated concentrations for $48 \mathrm{~h}$ were quantitated by cytokine array (mean $\pm \mathrm{SD} ; n=3$ ). ${ }^{\star} p<0.05$, ${ }^{* * *} p<0.001$ and ${ }^{\star * \star *} p<0.0001$ when compared with the sham treatment according to one-way ANOVA followed by Tukey's post hoc test.

NF- $\kappa \mathrm{B}$ signaling pathway in human MoDCs (Figures 4A,B). Furthermore, combined treatment activated phospho-p38, phospho-JNK, phospho-CREB, and phospho-c-Jun to a much greater extent than either treatment alone indicating that MAPK pathways were also synergistically activated in human MoDCs (Figure 4C). NF- $\mathrm{BB}$ and MAPK-signaling pathways promote the expression of many cytokines including that of IL-12p70 $(4,14,30)$. These results suggest that synergistic stimulation by $\mathrm{N} 1$ and $\mathrm{R} 848$ of NF- $\mathrm{KB}$ and MAPK transcription factors contributed to the induction of IL-12p70, IL- $1 \beta$, and TNF- $\alpha$ pro-inflammatory cytokines and maturation signals in human MoDCs.

\section{N1 Plus R848 Induce Type 1 IFN in Human MoDCs by Synergistic Activation of IRF3 and IRF7}

In addition to the induction of pro-inflammatory genes, $\mathrm{N} 1$ and R848 stimulation of human MoDCs also showed a critical role in enhancing the production of type 1 IFN. 
A

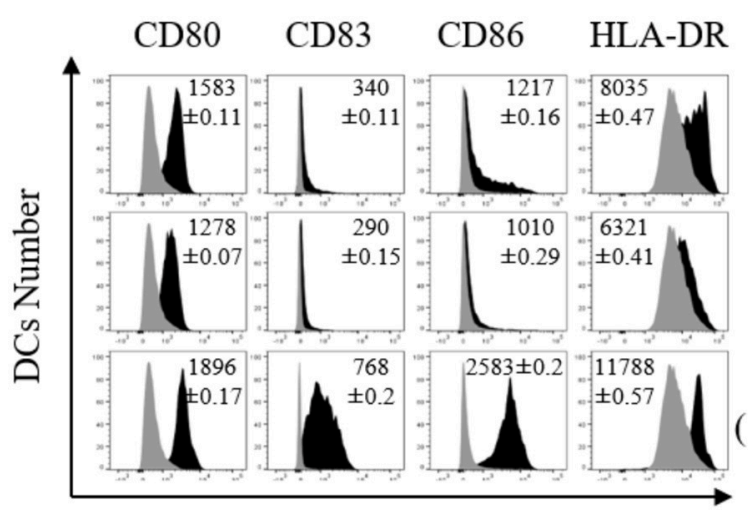

Fluorescence Intensity $(\log )$
N1

$(125 \mathrm{ng} / \mathrm{ml})$

R848

$(125 \mathrm{ng} / \mathrm{ml})$

$\mathrm{N} 1+\mathrm{R} 848$

$(125+125 \mathrm{ng} / \mathrm{ml})$

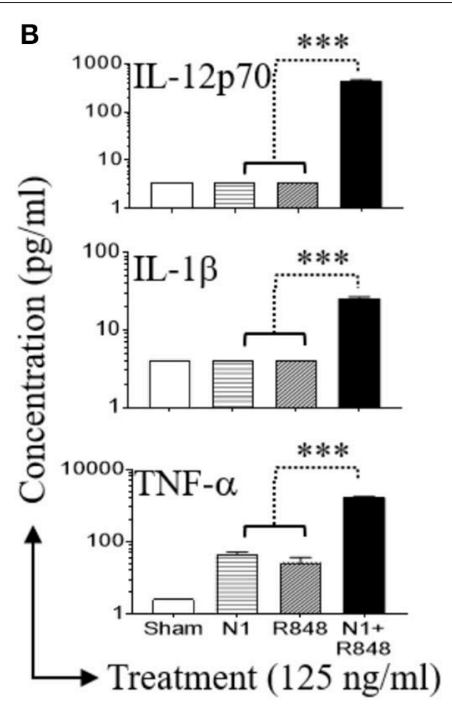

c

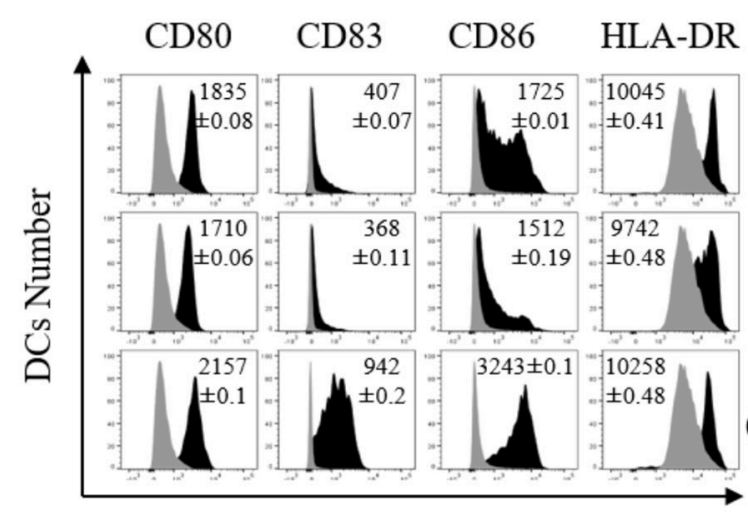

Fluorescence Intensity $(\log )$
N1

$(250 \mathrm{ng} / \mathrm{ml})$

R848

( $250 \mathrm{ng} / \mathrm{ml})$

$\mathrm{N} 1+\mathrm{R} 848$

$(250+250 \mathrm{ng} / \mathrm{ml})$

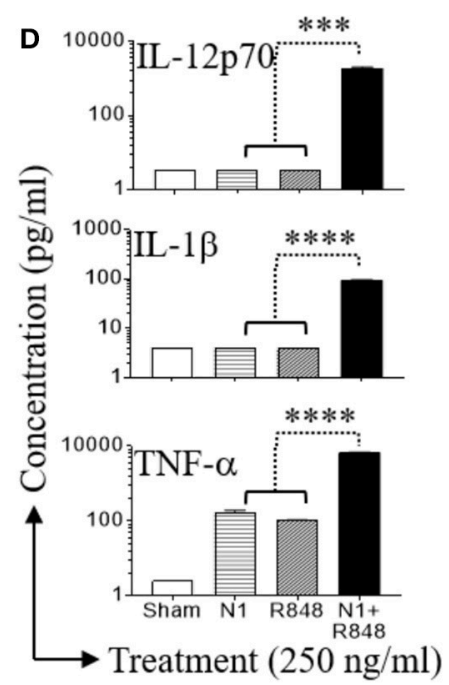

FIGURE 2 | N1 and R848 synergistically induce phenotypic maturation of human MoDCs. Human MoDCs were incubated at $5 \times 10^{5}$ cells/ml in the absence (sham) or presence of various concentrations of $\mathrm{N} 1$ and/or R848 for $48 \mathrm{~h}$ before they were analyzed for surface marker expression and cytokine production. (A,C) The expression of indicated surface molecules is shown as overlay histograms (gray area $=$ sham-treated) of one donor, with the average relative fluorescence intensity (geometric mean \pm SD) of three independent donors inscribed. (B,D) Cytokine levels in the culture supernatants were quantitated by cytokine array $($ mean \pm SD; $n=$ 3). ${ }^{* \star *} p<0.001$, and ${ }^{* \star * *} p<0.0001$ according to one-way ANOVA followed by Tukey's post hoc test.

To address whether $\mathrm{N} 1$ and R848 used common signaling pathways for inducing IFN in human MoDCs, we analyzed the activation status of IRF3 and IRF7 that have been described as a major transcription factors involved in IFN$\alpha$ and IFN- $\beta$ induction after their phosphorylation and translocation within the nucleus $(35,36)$. Human MoDCs treated with N1 (500 ng/ml) plus R848 (500 ng/ml) synergistically activated IRF3 as well as IRF7 transcription factors and increased their translocation to the nucleus (Figures 5A,B). This caused the robust activation of IFN- $\alpha 2$, IFN- $\alpha 4$, and IFN$\beta 1$ (Figures 5C-E) type 1 IFN in human MoDCs stimulated with N1 plus R848, which was greater than that induced by either single stimulant alone. Based on previous reports (8, 37 ), these data suggest that synergy between N1 plus R848 induced type 1 IFN through IRF3- and IRF7- dependent pathways that in turn enhanced the IL-12p70 production in activated human MoDCs. Furthermore, the CD4 $+\mathrm{T}$ cell expansion was also dependent on the signaling of type 1 IFN.

\section{N1 Dose Dependently Synergized With R848 in Stimulating Surface Marker Expression and Inducing Th1 Polarizing Cytokines Secretion by Mouse BMDCs}

Mouse BMDCs express a functional TLR7 receptor which is triggered by R848 (38). Stimulation of mouse BMDCs with $\mathrm{N} 1$ and $\mathrm{R} 848$ in combination demonstrated considerable 
A

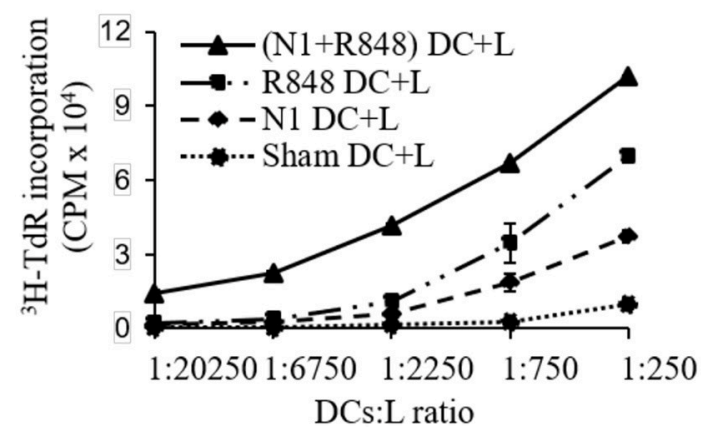

B

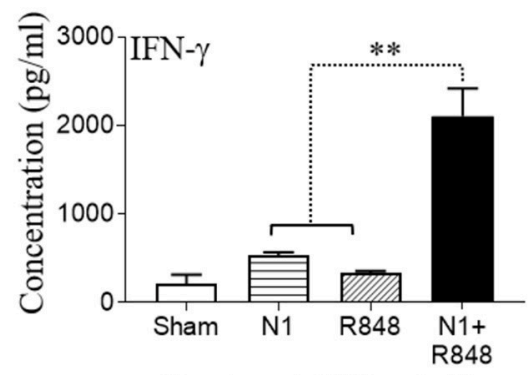

Treatment $(250 \mathrm{ng} / \mathrm{ml})$

C

Sham

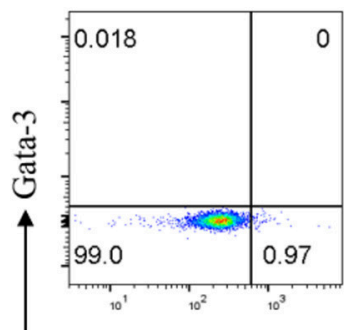

N1

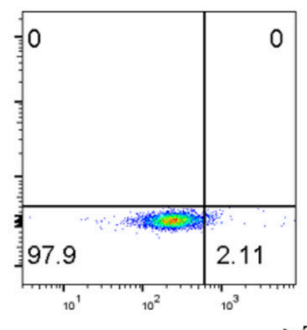

$\mathrm{R} 848$

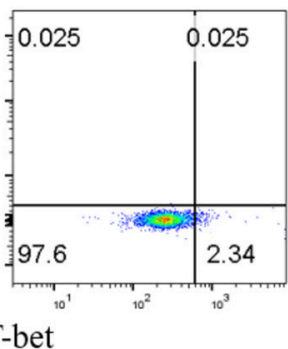

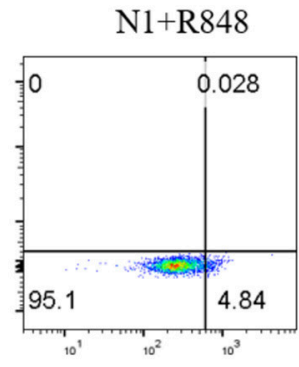

D

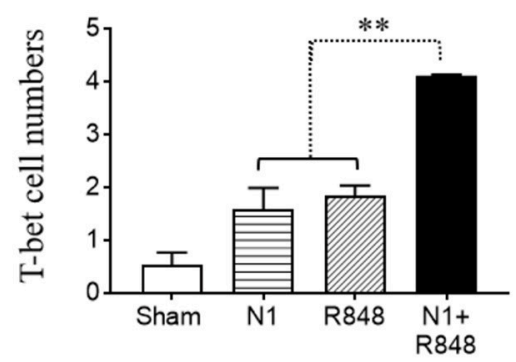

Treatment (250 ng/ml)
E

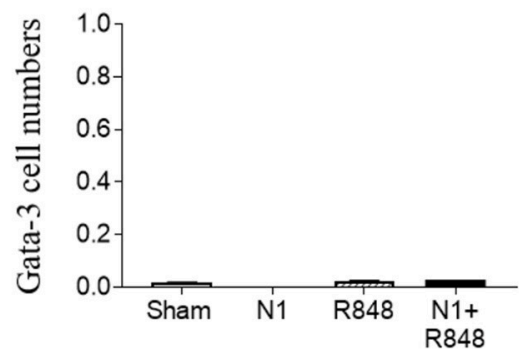

Treatment $(250 \mathrm{ng} / \mathrm{ml})$

FIGURE 3 | N1 and R848 synergistically induce functional maturation of human MoDCs. (A-E) Human MoDCs cultured in the presence or absence of N1 (250 ng/ml) and/or R848 (250 ng/ml) for $48 \mathrm{~h}$ were incubated in triplicate with allogenic human peripheral blood CD4+ T lymphocytes (L) (10 5 cells/well). (A) On day $4,1 \mu \mathrm{Ci}$ of $\left[{ }^{3} \mathrm{H}\right] \mathrm{TdR}$ was added to each well to pulse the cultures for another $18 \mathrm{~h}$. The proliferation was measured as the average (mean $\pm \mathrm{SD}$ ) of $\left[{ }^{3} \mathrm{H}\right] \mathrm{TdR}$ incorporation $(\mathrm{CPM})$ of triplicate wells. (B) IFN- $\gamma$ production by CD4+ T cells co-cultured with DCs (DCs:L = 1:250) for 3 days (mean \pm SD, $n=3$ ). (C-E) The expression of T-bet and Gata-3 by CD4+ T cells co-cultured with DCs (DCs:L = 1:250) for 3 days were measured by flow cytometry. (C) Representative dot plots. (D,E) The average (mean \pm SD) of triplicate wells. Shown is the results of one representative of three independent experiments obtained from different donors. ${ }^{\star \star} p<0.01$ according to one-way ANOVA followed by Tukey's post hoc test.

synergy (11). When treated with N1 (125 or $250 \mathrm{ng} / \mathrm{ml}$ ) or R848 (125 or $250 \mathrm{ng} / \mathrm{ml}$ ) by themselves, these ligands induced only very low levels of co-stimulatory (CD80 and CD86) and MHC class II (I-A/E) molecules on their surface (Figures 6A,C), as well as limited production of pro-inflammatory cytokine proteins (IL-12p70 and TNF- $\alpha$ ) (Figures 6B,D). However, the combination of N1 with R848 dose dependently upregulated co-stimulatory molecules as well as pro-inflammatory cytokine production at levels much higher than either ligand alone. Thus, we confirmed that N1 dose dependently synergized with R848 in the activation of mouse BMDCs.

\section{NI Plus R848 Also Synergistically Activated NF- $\mathrm{KB}$ and IRF Signaling in Mouse BMDCs}

A previous study reported that NF- $\mathrm{B}$ transcription factor regulates mouse BMDC activation and that inhibition of NF- $\kappa \mathrm{B}$ activation blocked maturation of mouse BMDCs in terms of upregulation of MHC complex and co-stimulatory molecules (39). The transcription factors IRF3 and IRF7 

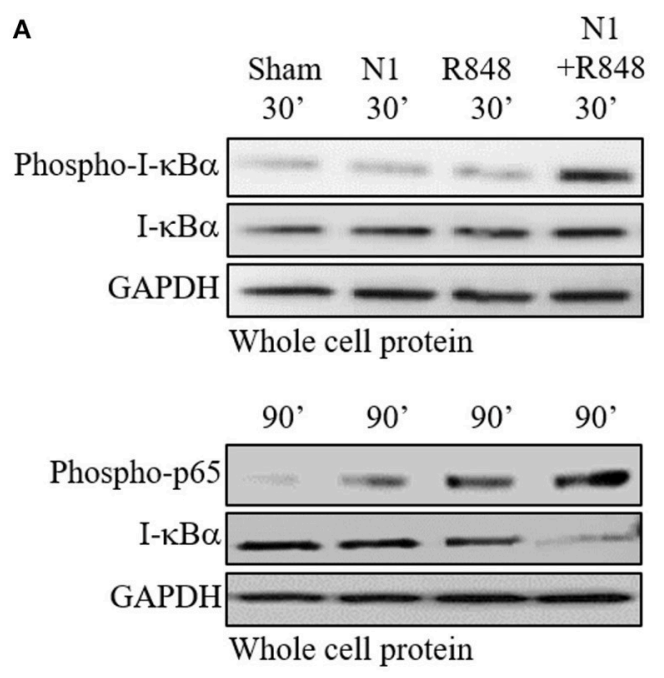

B

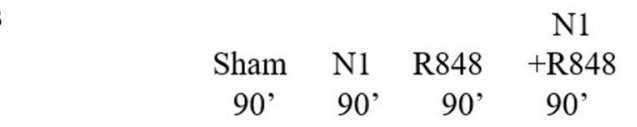

Phospho-p65

GAPDH

Cytoplasmic Fraction

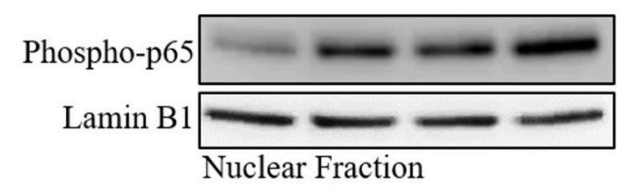

C

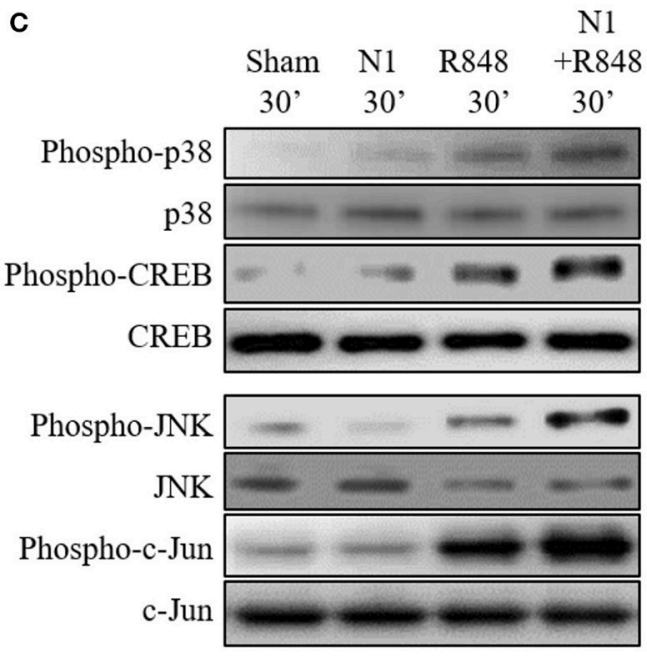

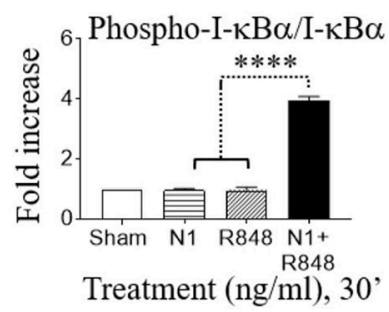

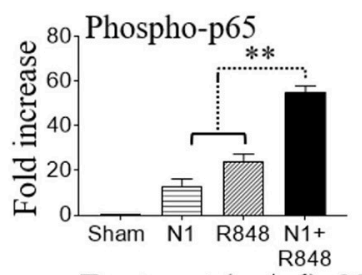

Treatment (ng/ml), 90'

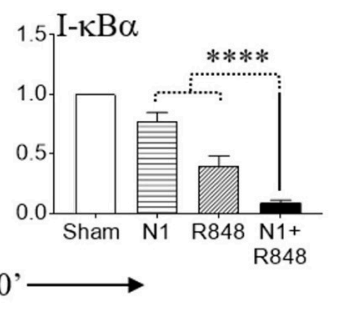

Nuclear phospho-p65/

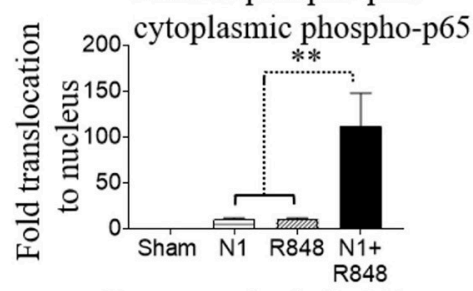

Treatment (ng/ml), 90'
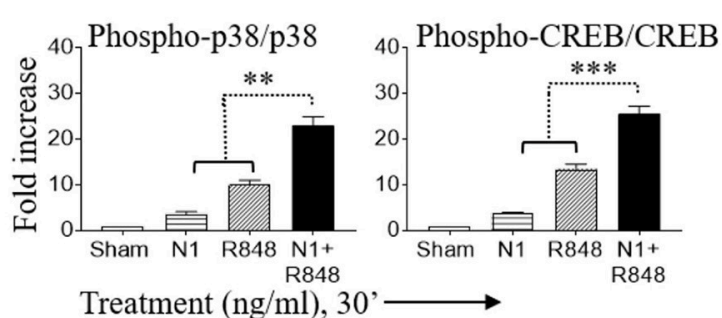

Treatment (ng/ml), 30'
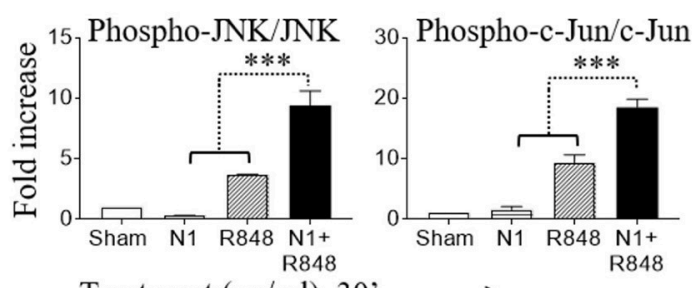

Treatment (ng/ml), 30'

FIGURE 4 | N1 and R848 synergistically activate NF-kB and MAPK signaling in human MoDCs. Serum-starved human MoDCs $\left(2 \times 10^{6}\right.$ cells/ml) were treated for 0-90 min with $\mathrm{N} 1(250 \mathrm{ng} / \mathrm{ml})$ and R848 $(250 \mathrm{ng} / \mathrm{ml})$ before they were solubilized in lysis buffer $\left(10^{6} \mathrm{MoDCs} / 0.1 \mathrm{ml}\right)$ to obtain whole cell lysates or in buffer $\left(2 \times 10^{6}\right.$ MoDCs/0.1 ml) for analysis of the translocation of proteins from the cytoplasmic to nuclear cell fractions. An identical amount of protein was loaded and separated by electrophoresis to detect the levels of phospho-I-kB $\alpha, \mathrm{I}-\mathrm{k} B \alpha$, phospho-p65, phospho-p38, p38, phospho-CREB, CREB, phospho-JNK, JNK, phospho-c-Jun, c-Jun, and GAPDH in whole cell lysates (A,C) or (B) cytoplasmic fraction of phospho-p65, GAPDH and nuclear fraction of phospho-p65, lamin B1. Quantitation of band intensities from three donors using ImageJ software were normalized against GAPDH or lamin B1. ${ }^{\star \star} p<0.01,{ }^{\star \star *} p<0.001$, and ${ }^{\star \star \star \star} p<0.0001$ according to one-way ANOVA followed by Tukey's post hoc test. 

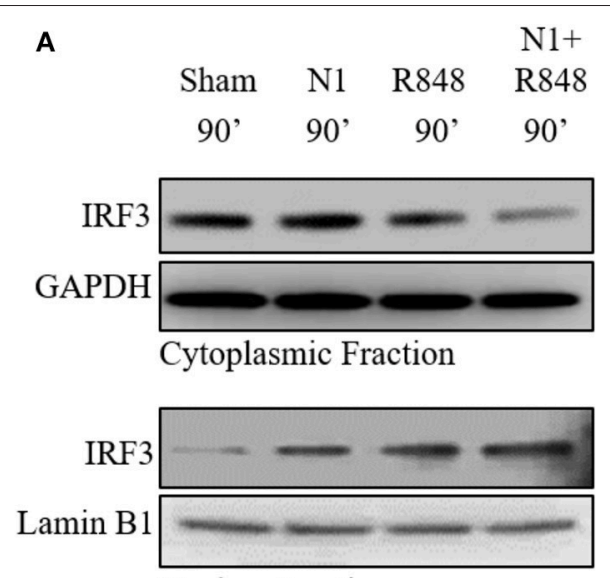

Nuclear Fraction

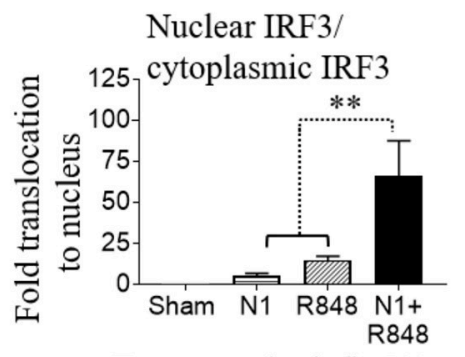

Treatment (ng/ml), 90'

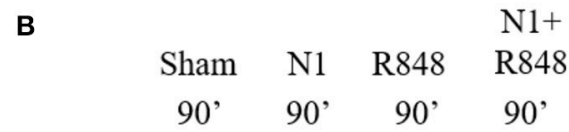

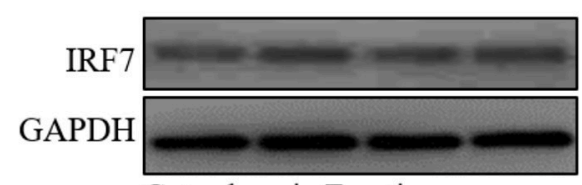

Cytoplasmic Fraction

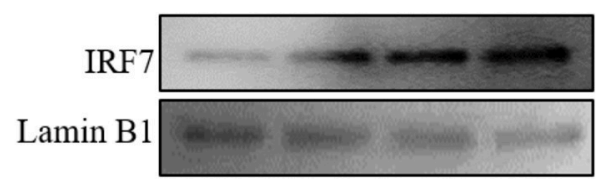

Nuclear Fraction

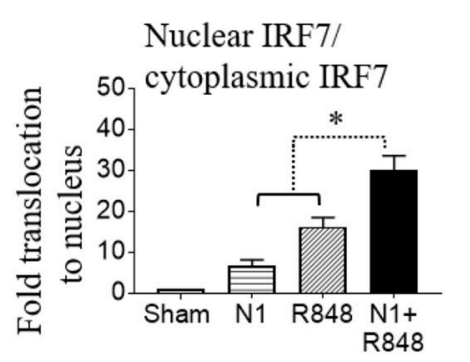

Treatment (ng/ml), 90'

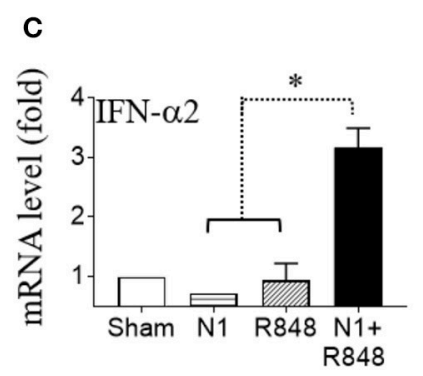

Treatment $(500 \mathrm{ng} / \mathrm{ml})$

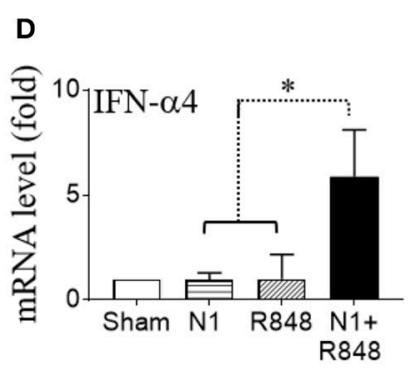

Treatment $(500 \mathrm{ng} / \mathrm{ml})$

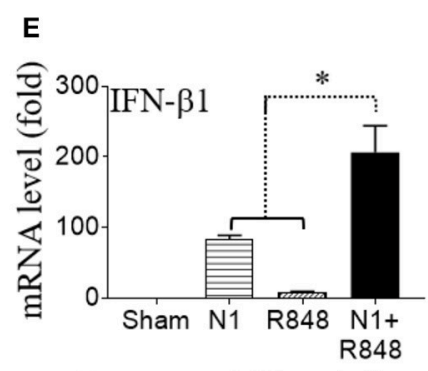

Treatment $(500 \mathrm{ng} / \mathrm{ml})$

FIGURE 5 | N1 and R848 synergistically activate IRF signaling as well as type 1 IFN responses in human MoDCs. (A,B) Serum-starved human MoDCs (2 × $10^{6}$ cells $/ \mathrm{ml})$ were treated for 0-90 min with $\mathrm{N} 1(500 \mathrm{ng} / \mathrm{ml})$ and R848 (500 ng/ml) before they were solubilized in buffer (2 $\left.\times 10^{6} \mathrm{MoDCs} / 0.1 \mathrm{ml}\right)$ for analysis of the translocation of proteins from cytoplasmic to nuclear cell fractions. An identical amount of protein was loaded and separated by electrophoresis to detect the levels of (A) cytoplasmic fraction of IRF3, GAPDH, and nuclear fraction of IRF3, lamin B1 or (B) cytoplasmic fraction of IRF7, GAPDH, and nuclear fraction of IRF7, lamin B1. Band intensities from three donors was quantified and normalized with GAPDH or lamin B1 using ImageJ software. (C-E) Human MoDCs were treated with N1 $(500 \mathrm{ng} / \mathrm{ml})$ and/or R848 (500 ng/ml) for $6 \mathrm{~h}$ before extraction of total RNA. The levels of IFN- $\alpha 2$, IFN- $\alpha 4$, and IFN- $\beta 1 \mathrm{mRNA}$ were quantitated by qPCR and shown as a fold increase over the sham treated DCs. Data are shown as the average (mean $\pm \mathrm{SD}$ ) of triplicates of one experiment representative of three. ${ }^{\star} p<0.05$, and ${ }^{* \star} p<0.01$ according to one-way ANOVA followed by Tukey's post hoc test.

coordinately regulate type 1 IFN induction in mouse BMDCs (40). IRF3 and IRF7 were also stimulated by TLR4 and TLR7/8 agonists and played an important role in the polarization of mouse BMDCs $(41,42)$. Therefore, we sought to determine whether pro-inflammatory cytokines and type 1 IFN production in mouse BMDCs by N1 plus R848 treatment 
A

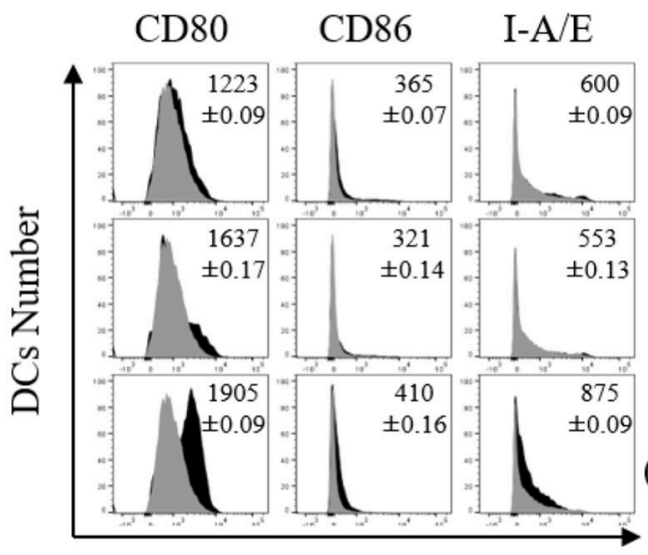

Fluorescence Intensity $(\log )$
B

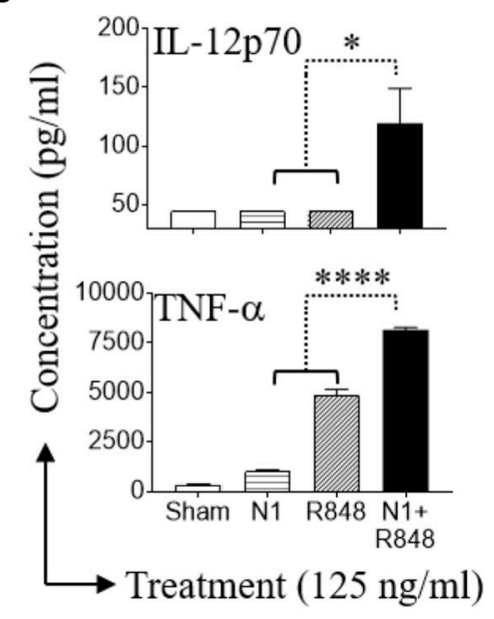

C

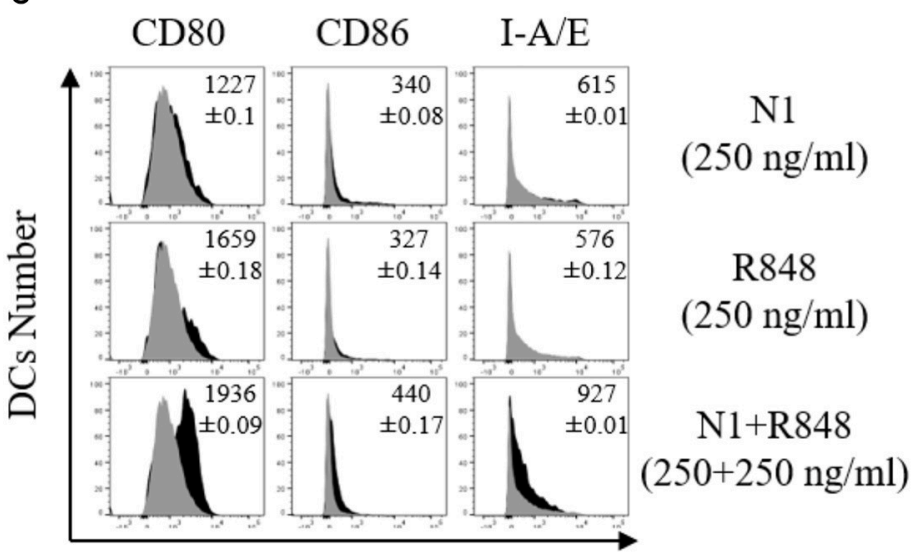

Fluorescence Intensity $(\log )$

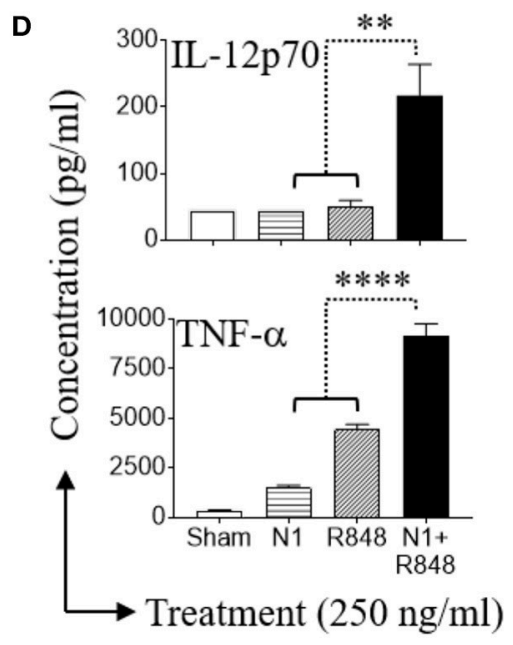

FIGURE 6 | N1 and R848 synergistically induce phenotypic maturation of mouse BMDCs. (A,C) Mouse BMDCs were incubated at $5 \times 10^{5}$ cells/ml in the absence (sham) or presence of $\mathrm{N} 1(125,250 \mathrm{ng} / \mathrm{ml})$ and R848 $(125,250 \mathrm{ng} / \mathrm{ml})$ for $48 \mathrm{~h}$ before they were immuno-stained and analyzed by flow cytometry for the expression of the indicated surface molecules [inscribed numbers are the average (geometric mean fluorescence intensity $\pm \mathrm{SD}$ ) of three batches of male mice; gray $=$ sham-treated]. (B,D) Cytokine levels in the culture supernatants for $48 \mathrm{~h}$ were quantitated by cytokine array (mean \pm SD; $n=3$ ). Shown are the results of one experiment representative of three from three different batches of male mice $(n=6)$. ${ }^{*} p<0.05$, ${ }^{\star *} p<0.01$, and ${ }^{* \star * *} p<0.0001$ according to one-way ANOVA followed by Tukey's post hoc test.

also contributed to the proliferation of $\mathrm{CD} 4+\mathrm{T}$ cells as well as their polarization into Th1 type cells. We treated mouse BMDCs with $\mathrm{N} 1$ (500 ng/ml) and R848 (500 ng/ml), and assessed the nuclear localization of phopho-p65, IRF3, and IRF7 transcription factors by Western blot. We found that these transcription factors were synergistically increased and translocated into the nucleus in mouse BMDCs when stimulated with N1 plus R848 (Figures 7A-C). As a result, type 1 IFN (IFN- $\beta 1$ ) was also synergistically induced in mouse BMDCs stimulated with $\mathrm{N} 1$ plus R848 to a much greater extent than by each stimulant alone (Figure 7D). These results agree with another report by O'Neill (36) suggesting that NF- $\mathrm{B}, \mathrm{IRF} 3$, and IRF7 signaling pathways played an important role in the synergistic upregulation of pro-inflammatory cytokines as well as type 1 IFN production by mouse BMDCs.

\section{Synergistic Effect of N1 Plus R848 Treatment Also Revealed by RNA-seq Analysis}

To examine the effect of $\mathrm{N} 1$ and R848 synergy on global gene expression, three human donor MoDCs were stimulated with sham, N1, R848, or N1 plus R848 for $4 \mathrm{~h}$. Many genes were upregulated or downregulated by the stimulation and our analysis of RNA-seq datasets measured 14,284 genes in each of 12 


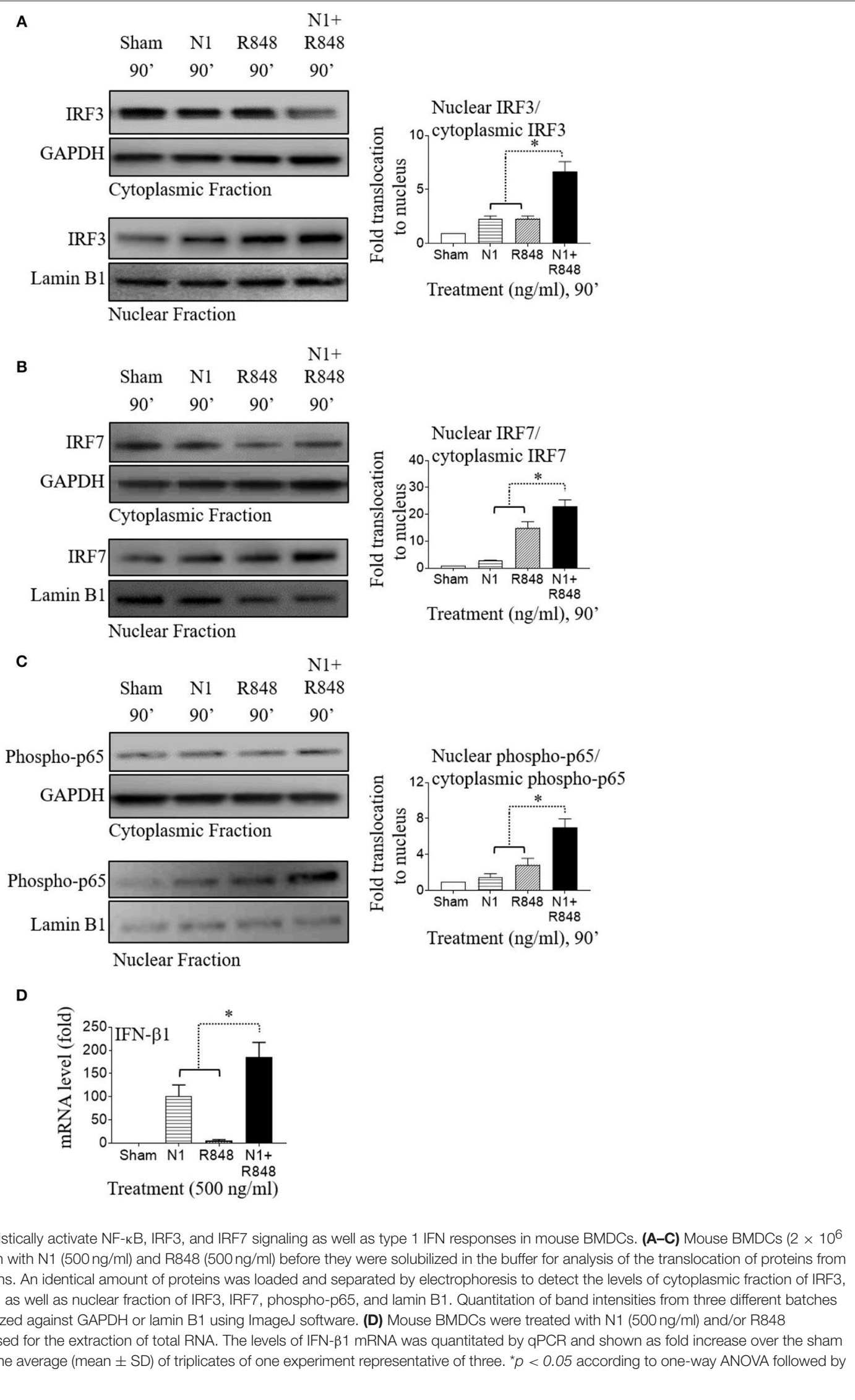


A

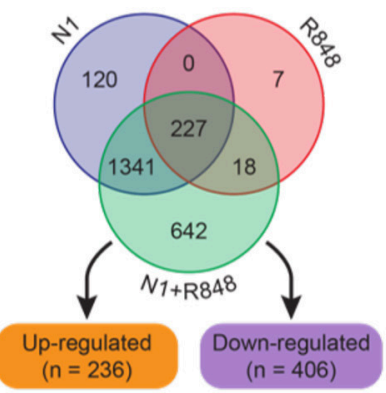

B

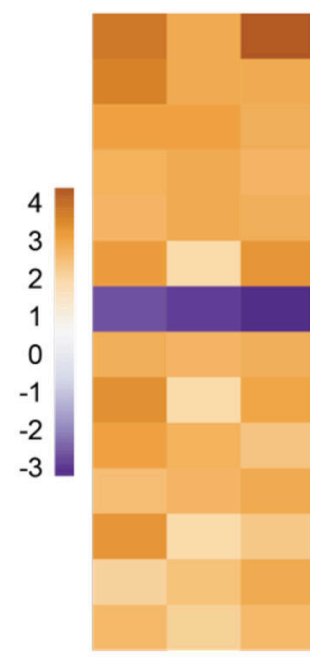

N1 R848 N1+ R848

C

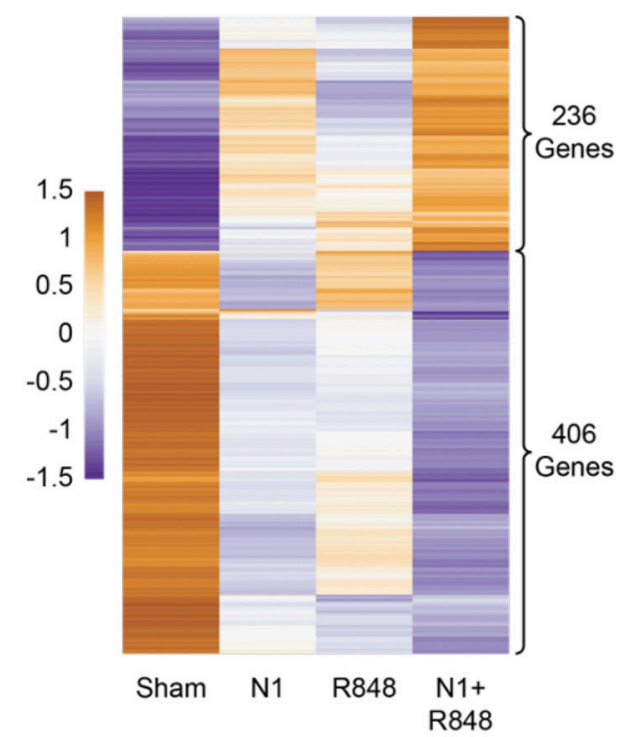

D

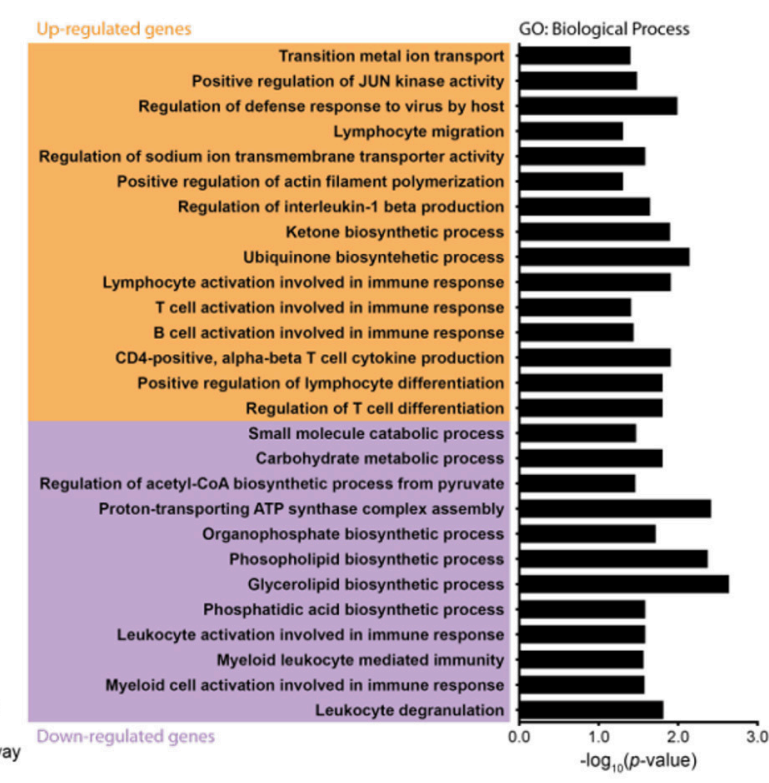

E

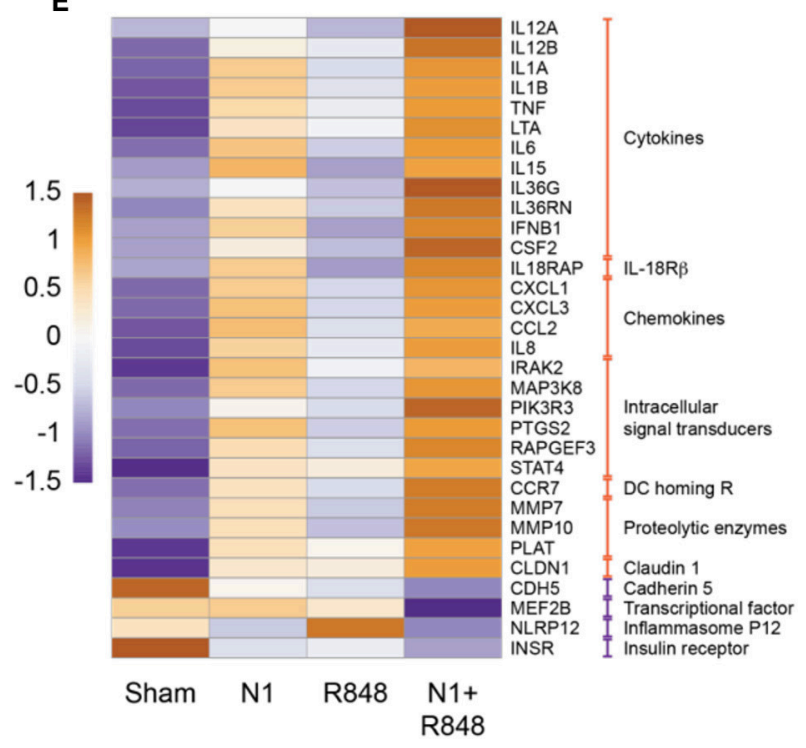

$\mathbf{F}$

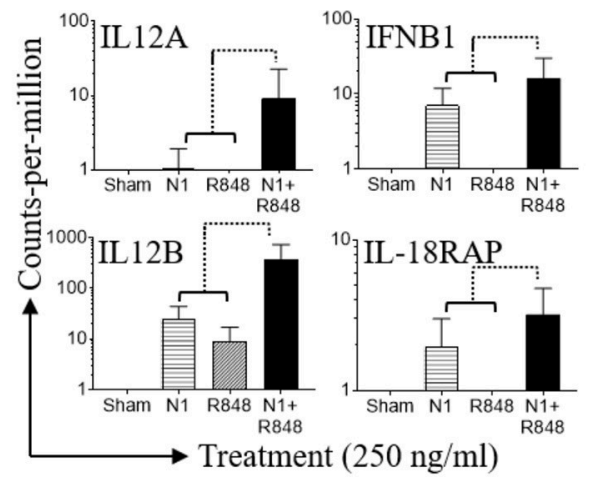

FIGURE 8 | Synergy of N1 and R848 as revealed by RNA-seq analysis. Human MoDCs from three donors were stimulated with N1 (250 ng/ml) and/or R848 $(250 \mathrm{ng} / \mathrm{ml}$ ) for $4 \mathrm{~h}$ before extraction of total RNA. (A) Venn diagram of 2355 genes out of 14,284 genes were found to be variable (adjusted $p<0.05$ and absolute fold (Continued) 
FIGURE 8 | change relative to sham $\geq 2.0$ ). (B) Heat map showing pathways identified as significantly (absolute activation z-score $\geq 2.0$ ) de/activated in all three experimental contrasts vs. sham. Cell values are activation z-scores and row centering has been applied. (C) Heat map showing the expression of 642 genes only found to be variable relative to sham when treated with N1 plus R848. (D) Results of gene ontology (GO) term analysis of the 642 genes exclusively variable in the N1 plus R848 treatment. Significant $(p<0.05)$ GO terms for the up- and down-regulated subsets of these genes are given; the bar graph visualizes log 10 -transformed, Bonferonni-corrected $p$-values for each term. (E) Heat map showing the expression of 32 selected genes with relevance to DCs maturation. All genes in this subset were included in the set of 2,355 unique variable genes as well as the significantly de/activated pathway analysis. (C,E) Expression values in these heat maps are $\log _{2}$-transformed, TMM-normalized counts-per-million (CPM). (F) Shown are the fold expression of CPM of 4 genes selected from 28 synergistic upregulated genes obtained from three donors. Orange shows relatively high expression while purple shows relatively low expression. Row centering and unit variance scaling have been applied. Rows are clustered using Euclidean distances and complete linkage.

samples (Figure S5A). After normalization and filtering, a total of 2,355 of these genes were found to be variable in at least one of the contrasts between an experimental treatment and sham (Figure S5B). Of these, 642 variable genes were perturbed only when N1 and R848 were both present, with 236 upregulated and 406 down-regulated relative to sham controls (Figures 8A,C). A gene ontology (GO) term analysis of these 642 genes revealed the majority to be involved in the synergistic upregulation of Tlymphocyte activation and differentiation pathways (Figure 8D). Pathway analysis revealed the DC maturation pathway as the most significantly activated in comparison with other activated pathways. In contrast, the peroxisome proliferator-activated receptor (PPAR) signaling pathway was most downregulated (Figure 8B). From the genes in these pathways, the most synergistically up- or downregulated 32 genes are in fact highly relevant to DC maturation, highlighting the synergistic effect of N1 plus R848 on DC maturation (Figure 8E). Of these 32 genes involved in DCs maturation, 28 gene transcripts that were synergistically upregulated involved cytokines, IL-18R $\beta$, chemokines, intracellular signal transducers, DC homing $\mathrm{R}$, proteolytic enzymes, as well as claudin 1 signaling pathway. Four gene transcripts were highly synergistically downregulated, including cadherin 5, the MEF2B transcriptional factor, inflammasome $\mathrm{P} 12$ as well as insulin receptor signaling pathways (Figure 8E).

Out of 28 most upregulated transcripts in response to treatment with $\mathrm{N} 1$ plus R848, four genes including $I L 12 A, I L 12 B$, $I F N B 1$, and $I L-18 R A P$ play critical roles in the polarization of CD4+ T lymphocytes into Th1 type cells. IL12A, a gene code for IL-12p35, was 1.2-fold upregulated by N1, not upregulated by R848, and 8.89-fold upregulated by N1 plus R848, indicating a clear synergistic effect between N1 and R848 (Figure 8F). IL12B, a gene coding for IL-12p40, was 27-fold upregulated by N1, 9fold upregulated by R848, and 328-fold upregulated by N1 plus R848 (Figure 8F). This again demonstrated a clear synergistic effect between N1 and R848. This synergy was also shown by the expression levels of IFNB1 and IL-18RAP in DCs stimulated with $\mathrm{N} 1$ and R848 alone or in combination (Figure 8F). Together with the data showing that treatment with N1 plus R848 synergistically induced IL-12p70 production in DCs (Figures 2, 6), it was clear that stimulation with N1 plus R848 triggered Th1-polarizing program in DCs. Therefore, RNA-seq data demonstrate that $\mathrm{N} 1$ plus R848 at the global gene expression level synergistically promotes DC maturation and subsequent upregulation of many genes in DCs that are involved in the polarization of CD4+ T cells into Th1-type effectors.

\section{DISCUSSION}

Conversion of tumor-infiltrating DCs from tolerogenic to immunogenic by providing the appropriate stimulation of maturation is critical for the induction of therapeutic antitumor immune responses characterized by the generation of IFN$\gamma$-producing Th1 and CTL effectors (43).We have previously reported that administration of $\mathrm{N} 1$ and $\mathrm{R} 848$ into mouse tumors induces tumor-specific curative immunity $(11,44)$ as a result of stimulating robust maturation of tumor-infiltrating DCs (11). Indeed, stimulation by $\mathrm{N} 1$ and R848 resulted in the synergistic upregulation of DC surface markers, production of pro-inflammatory cytokines and antigen-presenting capacity (Figures 2, 3). Global gene expression analysis by RNA-seq further demonstrated that $\mathrm{N} 1$ and R848 acted in synergy to promote full maturation of human DCs. Most of the genes whose expression were highly synergistically upregulated by N1 plus R848 belong to the DC maturation pathway (Figure $8 B$ ). The expression of many genes was changed only in response to both N1 plus R848 (Figures 8A,C). Furthermore, the 28 genes most highly synergistically upregulated by N1 plus R848 express products characteristic of full DC maturation, including pro-inflammatory cytokines, chemokines, intracellular signal transducers, and the chemokine receptor CCR7 responsible for DC homing to draining lymph nodes, a hallmark of full DC maturation (Figure 8E). Thus, the combination of N1 and R848 synergize to promote the full maturation of human DCs, which reinforces the idea of using N1 and R848 which is able to induce curative antitumor immunity in mice $(11,44)$ as having the potential to be translated into human usage.

How do N1 and R848 synergize in inducing DC maturation and generation of Th1-polarizing signals? Stimulation of both human and mouse DCs with N1 plus R848 resulted in synergistic activation of NF- $\mathrm{B}, \mathrm{MAPK}, \mathrm{IRF} 3$, and IRF7 signaling pathways (Figures 4A-C, 5A,B, 7A-C). These signaling pathways lead to the activation of many transcriptional factors (e.g., NF- $\kappa \mathrm{B}$, CREB, AP-1, IRF3, and IRF7), which, upon translocating to the nucleus, promote the transcription of genes characteristic of DC maturation/activation, including genes for cytokines (e.g., IL-12, IL-1 $\beta$, and TNF- $\alpha$ ), co-stimulatory molecules (CD80, CD83, and CD86), and MHC molecules (MHC class I and II). Furthermore, various transcription factors cooperate to synergistically upregulate the expression of genes characteristic of DCs activation, for example IL-12 upregulation requires both NF- $\kappa$ B and IRF (30, 45-47). Since N1 activates DCs predominantly by stimulating surface TLR4 and using both 
MyD88 and TRIF pathways (4), while R848 activates endosomal TLR7/8 using MyD88, but not the TRIF, pathway (14), it is likely that TLR4 stimulants can thus enhance the effects of TLR7/8 stimulants via the TRIF pathway. Therefore, cooperation of those pathways induced by $\mathrm{N} 1$ and R848 converging on the activation of various transcriptional factors presumably provides a key mechanism for their synergistic activation of DCs.

The second possible cause of the observed synergy may arise from the induction of type 1 IFN production and the subsequent positive feedback on DC activation. It was previously reported that activation of the IRF transcription factors downstream of TLR4 and TLR7/8 signaling result in the production of type 1 IFN (36). Synergy between TLR agonists is enabled by TLR4 mediated IRF3-initiated production of IFN $\beta 1$, which in turn also leads to higher IRF7 transcription factor synthesis. This positive feedback can result in a more efficient TLR7/8 signaling $(8,48)$. In our study, N1 plus R848 stimulation of DCs promoted the synergistic production of both IRF3 and IRF7 leading to greater secretion of type 1 IFN such as IFN- $\alpha 2$, IFN- $\alpha 4$, and IFN- $\beta 1$ than by single agonists alone (Figures 5C-E, 7D, 8E,F). Therefore, as shown by us and others induction of type 1 IFN plays an important role in furthering the cascade of gene expression after TLR signaling (49) and an autocrine loop of type 1 IFN contributes to enhanced production of bioactive pro-inflammatory cytokines such as IL12 p70 (8).

A third possible cause of the synergy of DC activation and immune responses induced by $\mathrm{N} 1$ and $\mathrm{R} 848$ can arise from the activation of distinct subsets of DCs by N1 and R848. In both humans and mice, TLR 4 and TLR7/8 are expressed by different subsets of DCs. pDCs selectively express TLR7/8 but not TLR4, whereas cDCs express functional TLR4, but not TLR7/8 (43, 50-53). R848, by engaging TLR7/8 in the endosomes, selectively activates $\mathrm{pDCs}$, leading to the production of type 1 IFN. N1, by triggering TLR4 on cell surfaces, activates cDCs (but not pDCs), promoting antigen uptake, processing, presentation, and the production of pro-inflammatory cytokines $(4,43,52,54)$. Therefore, R848 induced activation of pDCs through TLR7/8 in turn activates immature tumor-infiltration cDCs to become able to induce antitumor immunity. Thus, activation of distinct subsets of DCs by N1 and R848 can potentially result in more robust synergistic activation of DCs, particularly in vivo.

It has previously been reported that there is synergy between TLR4 agonist LPS and TLR7/8 agonist R848 in inducing a Th1-polarizing program in DCs (30). However, N1 is different from other TLR4 agonists such as LPS since it interacts with MD2 of the TLR4 receptor complex at a site that is different from where LPS binds (4), suggesting that there might be difference between N1+R848-induced and LPS+R848-induced DC maturation. In addition, $\mathrm{N} 1$ as an alarmin is endogenously produced and likely to have less deleterious effect than LPS in in vivo usage, which is particularly relevant in the context of implication for anticancer immunotherapy. We have in fact recently demonstrated that $\mathrm{N} 1$ and R848 administered in combination into established mouse tumors promoted more robust in vivo maturation/activation of tumor-infiltrating DCs (11) and consequently promoted greater antitumor immunity than either one alone in multiple mouse tumor models $(11,44)$. The possibility of utilizing the combination of N1 and R848 to promote therapeutic antitumor immunity in humans is being evaluated. N1 and R848 do synergize to induce the maturation/activation of human DCs in a way that potentially promotes the generation of beneficial human antitumor immune responses. Indeed, human DCs treated with N1 plus R848 preferentially stimulated the production of IFN- $\gamma$ and upregulation of T-bet by CD4+ T cells in an allogeneic MLR (Figure 3).

In conclusion, the current study has demonstrated that stimulation by $\mathrm{N} 1$ plus $\mathrm{R} 848$ results in remarkable synergistic activation of DCs through NF- $\mathrm{B}, \mathrm{MAPK}$, IRF3, and IRF7 signaling pathways. These signaling pathways promoted the synergistic production of Th1 polarizing cytokines, most importantly IL-12p70, TNF- $\alpha$, and IL-1 $\beta$, IL-18RAP, as well as type 1 IFNs (IFN- $\alpha$ and IFN- $\beta 1$ ). This in turn led to the enhanced expression of transcription factor T-bet and synergistic IFN- $\gamma$ production for synergistic expansion of Th1 type polarization. These findings strongly support the hypothesis that the combined stimulation of DCs by N1 plus R848 result in enhanced induction of Th1 immune responses, which is highly desirable for immunotherapeutic as well as antitumor vaccination strategies.

\section{ETHICS STATEMENT}

All experiments with mice were performed in compliance with the principles and procedures outlined in the National Institutes of Health Guide for the Humane Care and Use of Animals and were approved by the NCI at Frederick Animal Care and Use Committee.

\section{MATERIALS AVAILABILITY}

Recombinant human HMGN1 can be obtained through an MTA.

\section{AUTHOR CONTRIBUTIONS}

MA, DY, and JO for Conception and design. MA, DY, and AT for Development of methodologies and Acquisition of data. MA, DY, TM, and JO for Analysis and interpretation of data, as well as Writing, review, and/or revision of the manuscript. AT and DY for Administrative or technical support. DY and JO for Study supervision.

\section{FUNDING}

This project has been funded in part with Federal funds from the Frederick National Lab, National Institutes of Health, under Contract No. HHSN261200800001E. The content of this publication does not necessarily reflect the 
views or policies of the Department of Health and Human Services, nor does mention of trade names, commercial products, or organizations imply endorsement by the U.S. Government. This research was supported in part by the Intramural Research Program of NIH, Frederick National Lab, Center for Cancer Research. The publisher or recipient acknowledges right of the U.S. Government to retain a nonexclusive, royalty-free license in and to any copyright covering the article.

\section{REFERENCES}

1. McCarthy EF. The toxins of William B. Coley and the treatment of bone and soft-tissue sarcomas. Iowa Orthop J. (2006) 26:154-8.

2. Kawai T, Akira S. Toll-like receptors and their crosstalk with other innate receptors in infection and immunity. Immunity (2011) 34:637-50. doi: 10.1016/j.immuni.2011.05.006

3. Kawasaki T, Kawai T. Toll-like receptor signaling pathways. Front Immunol. (2014) 5:461. doi: 10.3389/fimmu.2014.00461

4. Yang D, Postnikov YV, Li Y, Tewary P, de la Rosa G, Wei F, et al. Highmobility group nucleosome-binding protein 1 acts as an alarmin and is critical for lipopolysaccharide-induced immune responses. J Exp Med. (2012) 209:157-71. doi: 10.1084/jem.20101354

5. Yang D, Chen Q, Yang H, Tracey KJ, Bustin M, Oppenheim JJ. High mobility group box-1 protein induces the migration and activation of human dendritic cells and acts as an alarmin. J Leukoc Biol. (2007) 81:59-66. doi: $10.1189 /$ jlb.0306180

6. Venereau E, Casalgrandi M, Schiraldi M, Antoine DJ, Cattaneo A, De Marchis F, et al. Mutually exclusive redox forms of HMGB1 promote cell recruitment or proinflammatory cytokine release. J Exp Med. (2012) 209:1519-28. doi: 10.1084/jem.20120189

7. Yang, Han Z, Alam MM, Oppenheim JJ. High-mobility group nucleosome binding domain 1 (HMGN1) functions as a Th1-polarizing alarmin. Semin Immunol. (2018) S1044-5323:30075-1. doi: 10.1016/j.smim.2018.02.012

8. Gautier G, Humbert M, Deauvieau F, Scuiller M, Hiscott J, Bates EE, et al. A type I interferon autocrine-paracrine loop is involved in Toll-like receptorinduced interleukin-12p70 secretion by dendritic cells. J Exp Med. (2005) 201:1435-46. doi: 10.1084/jem.20041964

9. Wei F, Yang D, Tewary P, Li Y, Li S, Chen X, et al. The Alarmin HMGN1 contributes to antitumor immunity and is a potent immunoadjuvant. Cancer Res. (2014) 74:5989-98. doi: 10.1158/0008-5472.CAN-13-2042

10. Del Corno M, Michienzi A, Masotti A, Da Sacco L, Bottazzo GF, Belardelli F, et al. CC chemokine ligand 2 down-modulation by selected Toll-like receptor agonist combinations contributes to $\mathrm{T}$ helper 1 polarization in human dendritic cells. Blood (2009) 114:796-806. doi: 10.1182/blood-2009-01-199406

11. Nie Y, Yang, Trivett A, Han Z, Xin H, Chen X, et al. Development of a curative Therapeutic Vaccine (TheraVac) for the treatment of large established tumors. Sci Rep. (2017) 7:14186. doi: 10.1038/s41598-017-14655-8

12. Vabret N, Bhardwaj N, Greenbaum BD. Sequence-specific sensing of nucleic acids. Trends Immunol. (2017) 38:53-65. doi: 10.1016/j.it.2016.10.006

13. Hemmi H, Kaisho T, Takeuchi O, Sato S, Sanjo H, Hoshino K, et al. Small anti-viral compounds activate immune cells via the TLR7 MyD88-dependent signaling pathway. Nat Immunol. (2002) 3:196-200. doi: 10.1038/ni758

14. Jurk M, Heil F, Vollmer J, Schetter C, Krieg AM, Wagner H, et al. Human TLR7 or TLR8 independently confer responsiveness to the antiviral compound R-848. Nat Immunol. (2002) 3:499. doi: 10.1038/ni0602-499

15. Demaria O, Pagni PP, Traub S, de Gassart A, Branzk N, Murphy AJ, et al. TLR8 deficiency leads to autoimmunity in mice. J Clin Invest. (2010) 120:3651-62. doi: 10.1172/JCI42081

16. Yin $\mathrm{T}, \mathrm{He} \mathrm{S}$, Wang $\mathrm{Y}$. Toll-like receptor $7 / 8$ agonist, R848, exhibits antitumoral effects in a breast cancer model. Mol Med Rep. (2015) 12:3515-20. doi: $10.3892 / \mathrm{mmr} .2015 .3885$

\section{ACKNOWLEDGMENTS}

We thank Ms. Joan Boxell for excellent managerial assistance.

\section{SUPPLEMENTARY MATERIAL}

The Supplementary Material for this article can be found online at: https://www.frontiersin.org/articles/10.3389/fimmu. 2018.02982/full\#supplementary-material

17. Lim JH, Catez F, Birger Y, Postnikov YV, Bustin M. Preparation and functional analysis of HMGN proteins. Methods Enzymol. (2004) 375:323-42. doi: 10.1016/S0076-6879(03)75021-6

18. Inaba $\mathrm{K}$, Inaba $\mathrm{M}$, Romani $\mathrm{N}$, Aya $\mathrm{H}$, Deguchi $\mathrm{M}$, Ikehara S, et al. Generation of large numbers of dendritic cells from mouse bone marrow cultures supplemented with granulocyte/macrophage colony-stimulating factor. J Exp Med. (1992) 176:1693-702. doi: 10.1084/jem.176.6.1693

19. Tewary P, de la Rosa G, Sharma N, Rodriguez LG, Tarasov SG, Howard OM, et al. $\beta$-defensin 2 and 3 promote the uptake of self or CpG DNA, enhance IFN- $\alpha$ production by human plasmacytoid dendritic cells, and promote inflammation. J Immunol. (2013) 191:865-74. doi: 10.4049/jimmunol.1201648

20. Yang D, Chen Q, Su SB, Zhang P, Kurosaka K, Caspi RR, et al. Eosinophilderived neurotoxin acts as an alarmin to activate the TLR2-MyD88 signal pathway in dendritic cells and enhances Th2 immune responses. J Exp Med. (2008) 205:79-90. doi: 10.1084/jem.20062027

21. Bolger AM, Lohse M, Usadel B. Trimmomatic: a flexible trimmer for Illumina sequence data. Bioinformatics (2014) 30:2114-20. doi: 10.1093/bioinformatics/btu170

22. Dobin A, Davis CA, Schlesinger F, Drenkow J, Zaleski C, Jha S, et al. STAR: ultrafast universal RNA-seq aligner. Bioinformatics (2013) 29:15-21. doi: 10.1093/bioinformatics/bts635

23. Li B, Dewey CN. RSEM: accurate transcript quantification from RNA-Seq data with or without a reference genome. BMC Bioinformatics (2011) 12:323. doi: 10.1186/1471-2105-12-323

24. Phipson B, Lee S, Majewski IJ, Alexander WS, Smyth GK. Robust hyperparameter estimation protects against hypervariable genes and improves power to detect differential expression. Ann Appl Stat. (2016) 10:946-63. doi: 10.1214/16-AOAS920

25. Edgar R, Domrachev M, Lash AE. Gene expression omnibus: NCBI gene expression and hybridization array data repository. Nucleic Acids Res. (2002) 30:207-10. doi: 10.1093/nar/30.1.207

26. Kramer A, Green J, Pollard J Jr, Tugendreich S. Causal analysis approaches in ingenuity pathway analysis. Bioinformatics (2014) 30:523-30. doi: 10.1093/bioinformatics/btt703

27. Bindea G, Mlecnik B, Hackl H, Charoentong P, Tosolini M, Kirilovsky A, et al. ClueGO: a cytoscape plug-in to decipher functionally grouped gene ontology and pathway annotation networks. Bioinformatics (2009) 25:1091-3. doi: 10.1093/bioinformatics/btp101

28. Metsalu T, Vilo J. ClustVis: a web tool for visualizing clustering of multivariate data using principal component analysis and heatmap. Nucleic Acids Res. (2015) 43:W566-70. doi: 10.1093/nar/gkv468

29. Banchereau J, Steinman RM. Dendritic cells and the control of immunity. Nature (1998) 392:245-52. doi: 10.1038/32588

30. Napolitani G, Rinaldi A, Bertoni F, Sallusto F, Lanzavecchia A. Selected Toll-like receptor agonist combinations synergistically trigger a $\mathrm{T}$ helper type 1-polarizing program in dendritic cells. Nat Immunol. (2005) 6:769-76. doi: $10.1038 /$ ni1223

31. van Haren SD, Dowling DJ, Foppen W, Christensen D, Andersen P, Reed SG, et al. Age-specific adjuvant synergy: dual TLR7/8 and mincle activation of human newborn dendritic cells enables Th1 polarization. J Immunol. (2016) 197:4413-24. doi: 10.4049/jimmunol.1600282 
32. Hajishengallis G, Lambris JD. More than complementing Tolls: complementToll-like receptor synergy and crosstalk in innate immunity and inflammation. Immunol Rev. (2016) 274:233-44. doi: 10.1111/imr.12467

33. Ghosh S, Karin M. Missing pieces in the NF-kappaB puzzle. Cell (2002) 109(Suppl.):S81-96. doi: 10.1016/S0092-8674(02)00703-1

34. Zhang FX, Kirschning CJ, Mancinelli R, Xu XP, Jin Y, Faure E, et al. Bacterial lipopolysaccharide activates nuclear factor-kappaB through interleukin-1 signaling mediators in cultured human dermal endothelial cells and mononuclear phagocytes. J Biol Chem. (1999) 274:7611-4. doi: 10.1074/jbc.274.12.7611

35. Hiscott J, Pitha P, Genin P, Nguyen H, Heylbroeck C, Mamane Y, et al. Triggering the interferon response: the role of IRF-3 transcription factor. $J$ Interferon Cytokine Res. (1999) 19:1-13. doi: 10.1089/107999099314360

36. O'Neill LA, Golenbock D, Bowie AG. The history of Toll-like receptors - redefining innate immunity. Nat Rev Immunol. (2013) 13:453-60. doi: $10.1038 /$ nri3446

37. Brinkmann V, Geiger T, Alkan S, Heusser CH. Interferon alpha increases the frequency of interferon gamma-producing human CD4+ T cells. J Exp Med. (1993) 178:1655-63. doi: 10.1084/jem.178.5.1655

38. Lee J, Chuang TH, Redecke V, She L, Pitha PM, Carson DA, et al. Molecular basis for the immunostimulatory activity of guanine nucleoside analogs: activation of Toll-like receptor 7. Proc Natl Acad Sci USA. (2003) 100:6646-51. doi: 10.1073/pnas.0631696100

39. Rescigno M, Martino M, Sutherland CL, Gold MR, Ricciardi-Castagnoli P. Dendritic cell survival and maturation are regulated by different signaling pathways. J Exp Med. (1998) 188:2175-80. doi: 10.1084/jem.188.11.2175

40. Lazear HM, Lancaster A, Wilkins C, Suthar MS, Huang A, Vick SC, et al. IRF-3, IRF-5, and IRF-7 coordinately regulate the type I IFN response in myeloid dendritic cells downstream of MAVS signaling. PLoS Pathog. (2013) 9:e1003118. doi: 10.1371/journal.ppat.1003118

41. Fitzgerald KA, Rowe DC, Barnes BJ, Caffrey DR, Visintin A, Latz E, et al. LPSTLR4 signaling to IRF-3/7 and NF-kappaB involves the toll adapters TRAM and TRIF. J Exp Med. (2003) 198:1043-55. doi: 10.1084/jem.20031023

42. Shevlin E, Miggin SM. The TIR-domain containing adaptor TRAM is required for TLR7 mediated RANTES production. PLoS ONE (2014) 9:e107141. doi: 10.1371/journal.pone.0107141

43. Colonna M, Trinchieri G, Liu YJ. Plasmacytoid dendritic cells in immunity. Nat Immunol. (2004) 5:1219-26. doi: 10.1038/ni1141

44. Han Z, Yang, Trivett A, Oppenheim JJ. Therapeutic vaccine to cure large mouse hepatocellular carcinomas. Oncotarget (2017) 8:52061-71. doi: 10.18632/oncotarget.19367

45. Trinchieri G. Interleukin-12 and the regulation of innate resistance and adaptive immunity. Nat Rev Immunol. (2003) 3:133-46. doi: 10.1038/nri1001

46. Bohnenkamp HR, Papazisis KT, Burchell JM, Taylor-Papadimitriou J. Synergism of Toll-like receptor-induced interleukin-12p70 secretion by monocyte-derived dendritic cells is mediated through p38 MAPK and lowers the threshold of T-helper cell type 1 responses. Cell Immunol. (2007) 247:7284. doi: 10.1016/j.cellimm.2007.07.008

47. Fischetti L, Zhong Z, Pinder CL, Tregoning JS, Shattock RJ. The synergistic effects of combining TLR ligand based adjuvants on the cytokine response are dependent upon p38/JNK signalling. Cytokine (2017) 99:287-96. doi: 10.1016/j.cyto.2017.08.009

48. Yamamoto M, Sato S, Hemmi H, Hoshino K, Kaisho T, Sanjo H, et al. Role of adaptor TRIF in the MyD88-independent toll-like receptor signaling pathway. Science (2003) 301:640-3. doi: 10.1126/science.1087262

49. Hertzog PJ, O'Neill LA, Hamilton JA. The interferon in TLR signaling: more than just antiviral. Trends Immunol. (2003) 24:534-9. doi: 10.1016/j.it.2003.08.006

50. Edwards AD, Diebold SS, Slack EM, Tomizawa H, Hemmi H, Kaisho T, et al. Toll-like receptor expression in murine DC subsets: lack of TLR7 expression by CD8 alpha+ DC correlates with unresponsiveness to imidazoquinolines. Eur J Immunol. (2003) 33:827-33. doi: 10.1002/eji.200323797

51. Ishikawa F, Niiro H, Iino T, Yoshida S, Saito N, Onohara S, et al. The developmental program of human dendritic cells is operated independently of conventional myeloid and lymphoid pathways. Blood (2007) 110:3591-660. doi: 10.1182/blood-2007-02-071613

52. Boonstra A, Asselin-Paturel C, Gilliet M, Crain C, Trinchieri G, Liu YJ, et al. Flexibility of mouse classical and plasmacytoid-derived dendritic cells in directing $\mathrm{T}$ helper type 1 and 2 cell development: dependency on antigen dose and differential toll-like receptor ligation. J Exp Med. (2003) 197:101-9. doi: 10.1084/jem.20021908

53. Merad M, Sathe P, Helft J, Miller J, Mortha A. The dendritic cell lineage: ontogeny and function of dendritic cells and their subsets in the steady state and the inflamed setting. Annu Rev Immunol. (2013) 31:563-604. doi: 10.1146/annurev-immunol-020711-074950

54. Asselin-Paturel C, Trinchieri G. Production of type I interferons: plasmacytoid dendritic cells and beyond. J Exp Med. (2005) 202:461-5. doi: $10.1084 /$ jem.20051395

Conflict of Interest Statement: The authors declare that the research was conducted in the absence of any commercial or financial relationships that could be construed as a potential conflict of interest.

Copyright (C) 2018 Alam, Yang, Trivett, Meyer and Oppenheim. This is an open-access article distributed under the terms of the Creative Commons Attribution License (CC BY). The use, distribution or reproduction in other forums is permitted, provided the original author(s) and the copyright owner(s) are credited and that the original publication in this journal is cited, in accordance with accepted academic practice. No use, distribution or reproduction is permitted which does not comply with these terms. 